University of Louisville

ThinkIR: The University of Louisville's Institutional Repository

Electronic Theses and Dissertations

$5-2012$

\title{
The role of human awareness on the spatial patterns of the tick- borne disease human monocytic ehrlichiosis in Missouri.
}

James Edward Nunn 1985-

University of Louisville

Follow this and additional works at: https://ir.library.louisville.edu/etd

\section{Recommended Citation}

Nunn, James Edward 1985-, "The role of human awareness on the spatial patterns of the tick-borne disease human monocytic ehrlichiosis in Missouri." (2012). Electronic Theses and Dissertations. Paper 1074.

https://doi.org/10.18297/etd/1074

This Master's Thesis is brought to you for free and open access by ThinkIR: The University of Louisville's Institutional Repository. It has been accepted for inclusion in Electronic Theses and Dissertations by an authorized administrator of ThinkIR: The University of Louisville's Institutional Repository. This title appears here courtesy of the author, who has retained all other copyrights. For more information, please contact thinkir@louisville.edu. 
THE ROLE OF HUMAN AWARENESS ON THE SPATIAL PATTERNS OF THE TICK-BORNE DISEASE HUMAN MONOCYTIC EHRLICHIOSIS IN MISSOURI

\title{
By
}

\section{James Edward Nunn III}

\author{
A Thesis \\ Submitted to the Faculty of the \\ College of Arts and Sciences of the University of Louisville \\ in Partial Fulfillment of the Requirements \\ for the Degree of
}

Master of Science

Department of Geography and Geosciences

University of Louisville

Louisville, Kentucky

May 2012 
Copyright 2012 by James Edward Nunn III

All rights reserved 
THE ROLE OF HUMAN AWARENESS ON THE SPATIAL PATTERNS OF THE TICK-BORNE DISEASE HUMAN MONOCYTIC EHRLICHIOSIS IN MISSOURI

By

James Edward Nunn III

A Thesis Approved on

April 5, 2012

By the following Thesis Committee:

Dr. Carol L. Hanchett

Thesis Director

Dr. Margath Walker

Dr. Scott LaJoie 


\section{ACKNOWLEDGEMENTS}

I would first like to thank my thesis advisor, Dr. Carol Hanchette for her guidance and direction over the past several years that has led to my interest in medical geography. I would also like to express my gratitude to Dr. Margath Walker for her unique perspective and guidance, without which I might not have taken this research project in the direction I did, and my third advisor, Dr. Scott LaJoie, for his invaluable insight, guidance, and time taken to work on this project with me. I also really appreciate all of the support and enthusiasm expressed by my fellow graduate students, as well as from friends and family. Lastly, I would like to specially express thanks to all the Postmasters of post offices of Ralls, Macon, Douglas and Carter Counties of Missouri, as well as all of the respondents who participated. Without their participation I would not have been able to complete this project. 


\begin{abstract}
THE ROLE OF HUMAN AWARENESS ON THE SPATIAL PATTERNS OF THE TICK-BORNE DISEASE HUMAN MONOCYTIC EHRLICHIOSIS IN MISSOURI James Edward Nunn III
\end{abstract}

April 5, 2012

Human monocytic ehrlichiosis (HME), a tick-borne disease that has recently surfaced in the United States, exists in regions where the tick vector population is established. This study utilizes methods that look beyond identifying high-risk regions, and investigates disparate awareness, self-perceived threat, and seriousness of HME to further enhance existing spatial modeling. The Health Belief Model provides a theoretical framework that encompasses the disease ecology aspect of medical geography to understand the relationship between people and their environment by surveying participants in study regions of Missouri. Results are suggestive that awareness differs between high/low incidence regions. Furthermore, education and income were found to be significant to overall awareness. The frequency of finding ticks, age, and overall concern and awareness were important factors in the decision to use preventative strategies against ticks. These results can be used to focus efforts by state health departments to increase awareness of this important disease. 


\section{TABLE OF CONTENTS}

PAGE

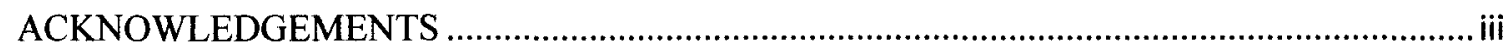

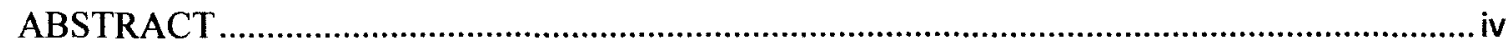

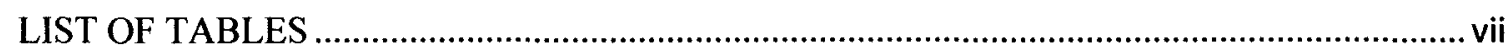

LIST OF FIGURES.......................................................................................................... vii

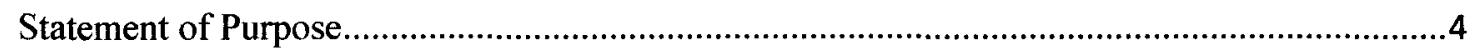

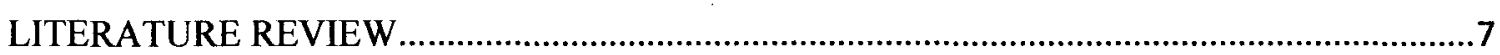

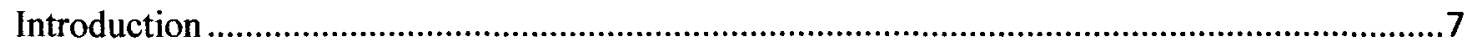

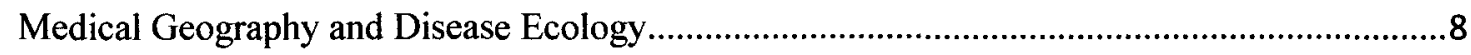

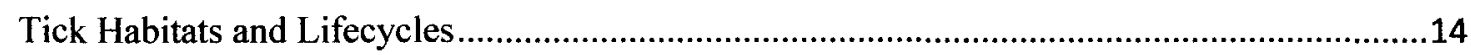

HME and Other Tick-borne Diseases in Missouri .................................................................16

HME Research and GIS applications ..........................................................................18

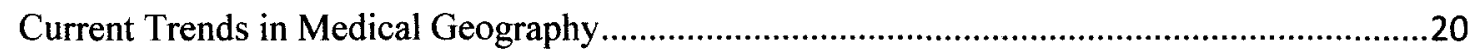

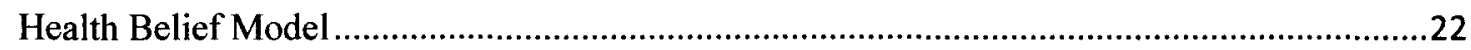

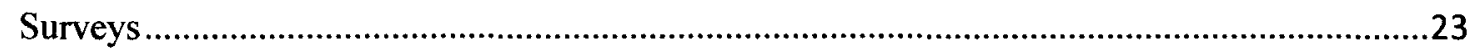

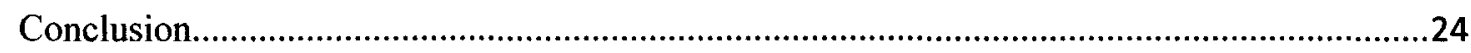

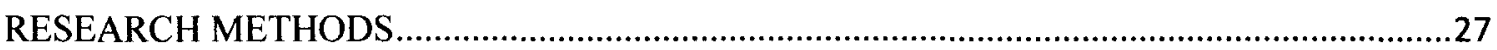

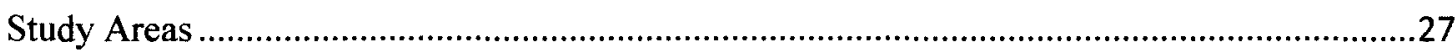

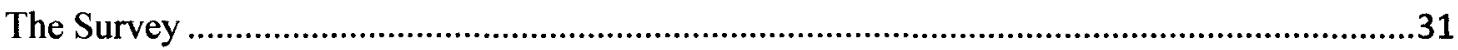

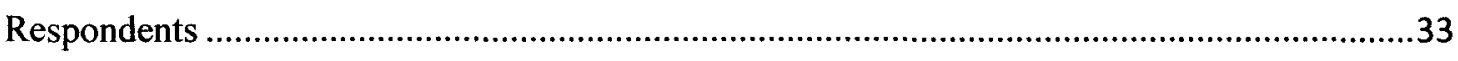

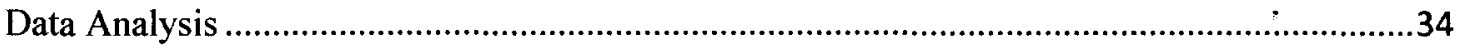

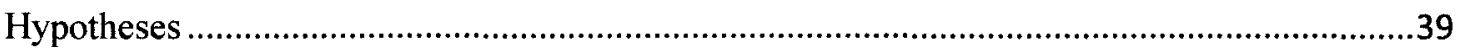

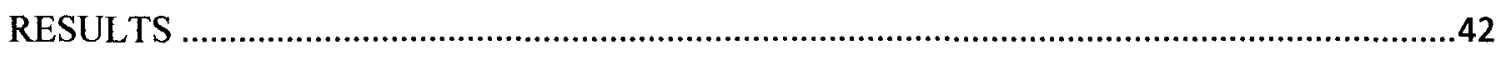




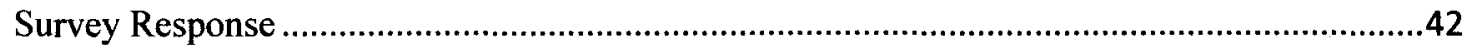

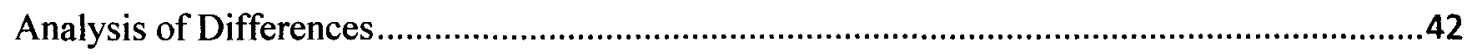

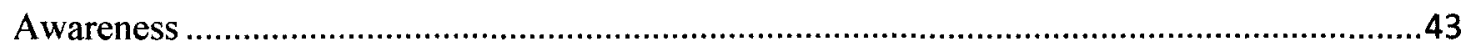

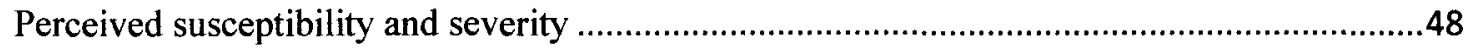

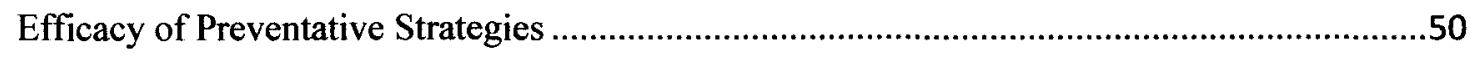

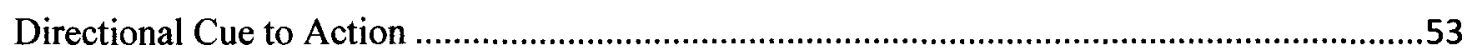

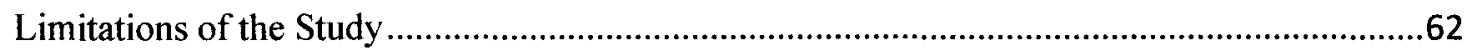

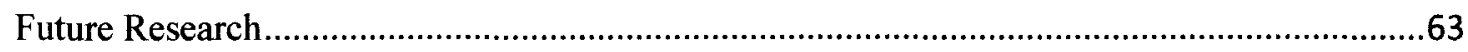

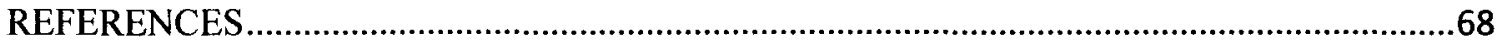

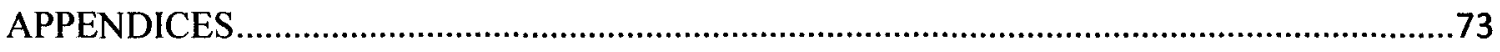

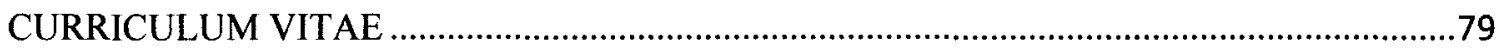




\section{LIST OF TABLES}

TABLE

PAGE

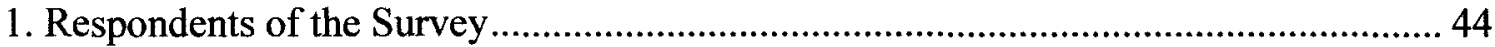

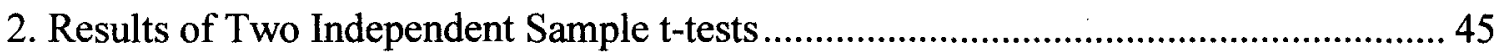

3. Multiple Linear Regression Results for Selected Independent Variables...................... 47

4. Discriminant Variables of Use of Preventative Measures Model ................................... 54

5. Discriminant Analysis Results of the Preventative Measures Model ............................ 54 


\section{LIST OF FIGURES}

FIGURE

PAGE

1. Disease Ecology Triangle ................................................................................... 10

2. Photograph of the Lone Star Tick ........................................................................... 15

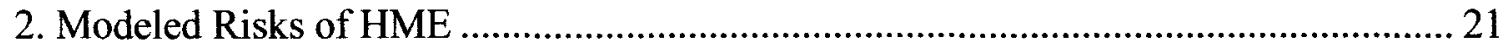

3. Average Actual Annual Incidence of HME in Missouri................................................ 28

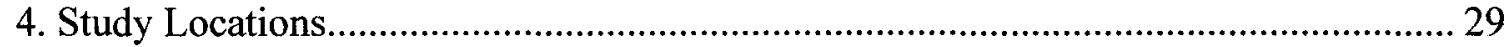

5. Post Office Sites................................................................................................... 30

6. Awareness verses Actual Tick Diseases in Missouri...................................................... 48

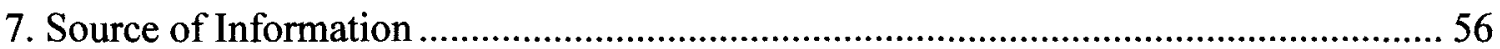




\section{CHAPTER I}

\section{INTRODUCTION}

Microbial pathogens that have deleterious effects on human health have been important factors that have shaped our history. Human infectious diseases that are transmitted by arthropod insect and arachnid vectors such as mosquitoes and ticks have become increasingly important on a global scale and can be debilitating and fatal to humans (Gubler 1998; Mahy 2004; CDC 2011; WHO 2011). Tropical diseases such as malaria and dengue that are spread by mosquitoes in developing countries of Africa and Asia have caused the deaths of millions of people and have debilitated millions more (Gubler 1998; WHO 2011). To understand where these diseases are occurring, attention has been placed on understanding the ecological distribution and preferred environmental habitats of the arthropod vectors that are responsible for the transmission of the disease causing pathogens (Gratz 1999; Mellor 2004).

In the United States, the Centers for Disease Control and Prevention (CDC) and other research foundations have focused attention on vector-borne diseases that are common in a more temperate climate region. Zoonotic diseases such as Lyme disease, West Nile virus, and Rocky Mountain spotted fever are a few vector-borne diseases that are common in the U.S. (Grubler 1998; CDC 2011a). Recently, the emergence of the new tick-borne disease, human monocytic ehrlichiosis (HME), out of the central part of the United States, has resulted in an increasing need to understand the spatial patterns of 
these diseases and what factors are important in allowing these diseases to occur in certain locations (Lockhart et al. 1997; Stein et al. 2008; CDC 2011a).

The history of HME in the United States is a recent one. In the spring of 1986 an Arkansas resident was admitted to the hospital with severe symptoms of an unknown illness. It was not until the patient described having been bitten by several ticks after visiting an area of rural northern Arkansas two weeks before did it become evident that the cause of this patient's symptoms could be due to a disease spread by ticks. After an incorrect diagnosis of Rocky Mountain spotted fever, a common disease known to be spread by ticks in the eastern part of the United States, the pathogen was finally identified as a bacterial agent that had only been seen solely in animals up until that point.

In the years following what was then an unknown illness, clinical studies identified several hundred human cases involving this pathogen now identified as Ehrlichia chaffeensis exhibiting moderate and sometimes fatal symptoms (Paddock \& Childs 2003). As of today there are two main Ehrlichia infections recognized: human granulocytic ehrlichiosis (HGE) and human monocytic ehrlichiosis (HME), termed so based on the human targeted body cells. In the United States, HME is more prevalent and is the focus of this study.

HME is a bacterial infection that is spread to humans when the lone star tick (Amblyomma americanum) that is infected with the Ehrlichia bacterium bites an unsuspecting human and transmits the disease causing pathogen into the blood of the victim (Lockhart et al. 1997; Paddock \& Childs 2003). Once a person has become infected, symptoms may develop between 1-2 weeks after exposure. In most cases, the symptoms of an HME infection are mild and may go unnoticed. In others, however, 
symptoms may become severe enough for an individual to be hospitalized. Typical symptoms are in combinations of fever, headache, chills, muscle pain, and nausea and vomiting. If not treated, or not correctly diagnosed, an HME infection may become fatal. The current fatality rate is $1 \%$, a decrease from recent years (CDC 2011a). Since HME has become a reportable disease in the U.S., the number of reported cases has increased. Due to increased knowledge and faster diagnosis, the fatality of HME has decreased from its peak of $4 \%$ to its current $1 \%$ (CDC2011a). However, long incubation periods and limited knowledge of tick disease risks may render much of the population at risk (Gould 2008; Meade \& Emch 2010; CDC 2012).

In 2008 alone, there were more than 900 reported cases of HME in the United States; $20 \%$ of these came from Missouri, the state with the highest incidence (CDC 2010). In 2007 and 2008, 202 and 198 cases, respectively, were reported in Missouri (CDC 2009; CDC 2010). GIS risk analysis by Wimberly et al. (2008b) and Yabsley et al. (2005) has illustrate that HME is highly endemic to Missouri. Mapping actual cases in Missouri and comparing these results to the models show that these risk models overestimate the occurrence of HME. To fully understand the observed spatial variability of HME requires a new perspective that considers the ecology of not only the ticks and preferred habitats, but also the relationship between humans and their surrounding environment. 


\section{Statement of Purpose}

Transmission of the Ehrlichia pathogen requires human contact with ticks, which most of the time will occur in the natural tick habitats. Therefore, awareness of tickborne diseases and self perceived risks, knowledge and use of preventative practices, and health information from health departments all play a key role in assessing the potential risks of contracting vector-borne diseases (Herrington et al. 1997; Herrington 2004;

Butterworth et al. 2010). With more individuals participating in outdoor occupational or leisure activities that may place them at risk of coming in contact with ticks, a focus on the people's awareness and perceived threats and seriousness of tick diseases may shed light on these components.

This study considers the awareness and perceived susceptibility of tick-borne diseases of residents of selected study counties of Missouri. The main purpose of this study stems from the review of GIS-based literature that suggests the need to expand the use of other methodologies in order to fully understand the observed spatial patterns of HME. With the high occurrence of this disease in Missouri, this region provides a prime location to study this idea. This has been done by comparing two study counties of reported high reported incidence of $\mathrm{HME}$ and two study counties with low reported incidence of HME and surveying residents of these locations to determine if there is any significant difference in awareness, perceived susceptibility, and use of preventative strategies. These surveys measure elements of the Health Belief Model (HBM), which include residential awareness, perceived susceptibility, and perceived severity. This study also examines the socio-demographic factors that may be significant to the 
respondents' overall awareness and perceived susceptibility to HME and other tick-borne diseases.

Missouri was chosen as a study location because of its high HME incidence between 2005 and 2009 (CDC 2007, 2008, 2009, 2010, and 2011). GIS-based research on HME in the southeastern and south-central regions of the United States has demonstrated that in much of this region, including most areas of Missouri, the tick vector responsible for transmitting the Ehrlichia pathogen is endemic. However, actual distribution of reported HME cases by county is not uniform. This research expands on previous research by using qualitative analysis to determine the relationship of awareness of residents of ticks and tick-borne diseases and the current distribution of the disease.

Research on tick-borne and other vector-borne diseases has been limited to understanding the ecology of the vector and preferred natural habitats as a way to identify regions where populations are likely to be established (Guerra et al. 2002; Yabsley et al. 2005; Stein et al. 2008). Little research has been done on understanding the relationship between the vectors and at risk population and no literature has been found that uses these methods of understanding the relationship between the lone star tick and populations at risk of contracting the HME causing pathogen. Furthermore, this study is the first known to investigate the disparities between actual reported cases and modeled endemic regions by considering the level of awareness and perceived risks.

The transmission of the pathogen that causes HME requires a set of important parameters that are not fully considered in spatial at-risk mapping. First, the tick vector must be present in the region of interest. Within that region, the bacterial pathogen must be established in the natural animal host of the white-tailed deer population and the tick 
vector. Because ticks are not very mobile species, the most important parameter to consider is the human population that may come in contact with infected ticks in these regions.

The relationship people have with their environment, or how the perceive their surroundings, has important consequences to their risk of contracting diseases. In order to fully understand the spatial distribution of HME in Missouri, this study uses a different approach that encapsulates not only the distribution of suitable habitats of where tick populations are likely to be established, but also the residents' awareness of ticks and tick-borne diseases and HME within this region (Herrington 2004). 


\section{CHAPTER II \\ LITERATURE REVIEW}

\section{Introduction}

The study of geographical occurrence of diseases and health disparities is an interest held by those in the field of medical geography (Meade \& Emch 2010). Within the context of medical geography is the interest and quest to understand why diseases occur where they do, and what causes them to occur at that location or region. Environmental factors often play a critical role in causing or exacerbating the spread of diseases and determining where certain diseases occur. For mosquito and tick-borne diseases, the environmental factors that are important in determining where these diseases occur often reflect where the mosquito or tick vector themselves can be established. Rainfall and rainwater drainage are just a couple of natural and built environments important to mosquitoes and the diseases they spread (Ozdenerol et al. 2008). Soil type, forest cover, and temperature are a few factors important to the occurrence of tick-borne diseases (Guerra et al. 2002; Yabsley et al. 2005; Wimberley et al. 2008a; 2008b; Stein et al. 2008).

The tick-borne disease of Human Monocytic Ehrlichiosis (HME) is a complex one that requires the presence of a tick infected by the Ehrlichia pathogen to bite and transmit this disease to a human. These three variables must all be present for the transmission of the HME causing pathogen to even occur. Understanding why ticks 
thrive where they do, environmental variables that allow or hinder tick population establishment, and what the relationship is with the bacterial pathogen and the arachnid vector are the foci of HME research. Little, if any, research has been done to consider the connection between the tick vector and the human, and how awareness of risks of ticks and tick-borne diseases shape the spatial patterns of this disease.

\section{Medical Geography and Disease Ecology}

Medical geography has existed much longer than the expression, and has undergone many developmental and shaping changes to attempt to explain why and where diseases occur, who becomes ill and who does not, and interactions of society with the environment (Meade \& Emch 2010). More than 2000 years ago this concept was recognized by Hippocrates (460-377 B.C.) with the importance of air, water, and place, and since then medical geography has developed into an important discipline to understand the spatial locations of disease. Now medical geography is defined as a holistic discipline that incorporates a number of techniques, concepts and theories, both originating within geography and extending to other related disciplines (Meade \& Emch 2010).

The idea of the inclusion of a number of theories and concepts opens the door for the insertion of related theories and philosophical ideas that can be fused within the discipline of medical geography. The geographical portion of the discipline is interested in investigating the locale of health-related topics ranging from disease occurrence and prevalence, healthcare systems and their functionality, as well as how they are related in a 
cultural, societal, and environmental sense. Because of this, medical geography uses spatial analysis as a way of interpreting the geographical aspect of these topics.

The perception of place, then, has become an important developing concept in understanding the distribution of disease and health disparities (Kearns 1993; Kearns \& Moon 2002; Rangan \& Kull 2009). The term place is defined as more than merely a geographic location, or a pinpoint in space, but rather as incorporating economic, environmental, and social processes within the society, and the overall interaction societies have with each other and the environment (Gregory et al. 2009). Traditional use of place in medical geography has been as a space where activities and events occur. Kearns and Moon (2002) demonstrate that a closer look at what constitutes place has allowed for multilevel perspectives on the class of society and the ability to recognize health inequality, as well as to recognize the strata of social class within the society.

Within the discipline of medical geography is the subdiscipline of human ecology of disease (Meade \& Emch 2010). A term that is used in many other disciplines, including anthropology and epidemiology, human ecology of disease is focused on the social relationship of populations and the interaction of human populations with the surrounding environment (Meade \& Emch 2010). This interaction is considered when investigating health related issues that include recognizing the impact of social, political, economic, and climatic factors that are important when considering the spatial distribution of diseases (May 1996; King 2010).

An important framework to consider when investigating infectious diseases within the context of disease ecology is the triangle of human ecology (Figure 1). 
Age, Race, Sex, Immune status

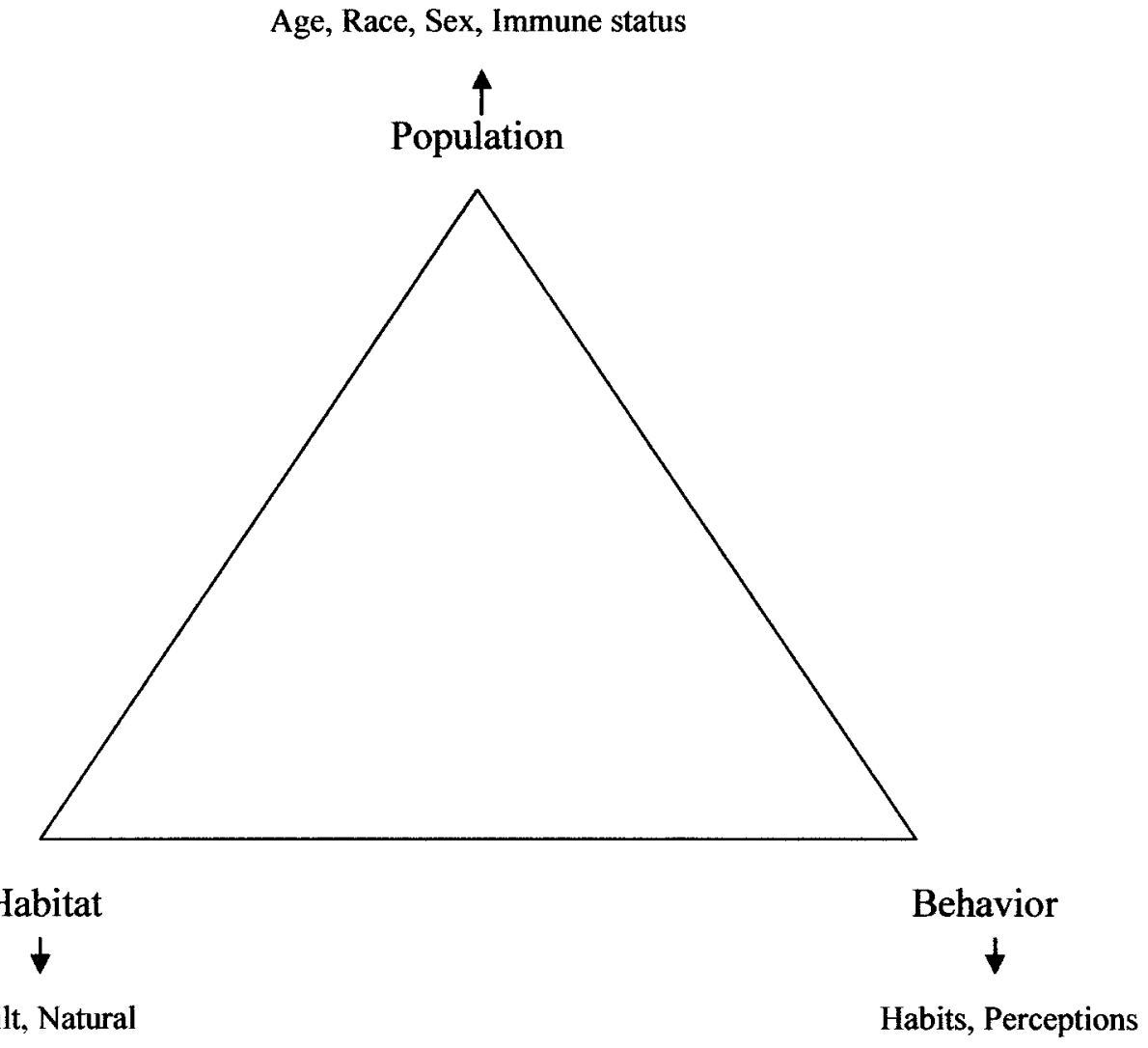

Figure 1. Diagram of human disease ecology triangle (Adapted from Meade \& Emch 2010).

Composed of three vertices, each one represents imperative factors that need to be considered in the spread of human diseases and human health (Meade \& Emch 2010). This framework allows researchers to organize the relationship among the variables of the human population, habitat, and behavior and assess important links that may otherwise be overlooked.

The population point of the triangle considers the at-risk populations themselves and includes factors of gender, age, and genetic susceptibility. Habitat includes the natural environment, built environment of individual homes and urban areas, and social 
locations of towns and cities. Lastly, behavior is how the population regards their own risk of disease, and the technology and preventative methods that are available to them, such as insect repellent. The implication of the triangle of human ecology of health for this research makes clear the question regarding the populations at-risk of contracting a tick-borne illness, their behavior, including preventative practices and knowledge of these diseases, and their interaction with their surrounding natural environment where they may come in contact with ticks.

Understanding why these factors are important in determining susceptibility to HME is an attempt to fuse the social-environmental relationship that has in the past been considered separately (Litva \& Eyles 1995; Mayer 1996; Dyke 1999 King 2010; Zimmerer 2007). Where many studies have often looked at just the environmental variables responsible for the establishment of disease-causing pathogens and the vectors that transmit them, this research is an attempt to consider the fusion of the social and natural environment through the scope of human disease ecology.

\section{Population}

Considering the population that is susceptible to diseases involves identifying those who are at greatest risk. Population factors could include the genetics, or genetic susceptibility, to diseases such as cystic fibrosis (Meade \& Emch 2010). Population structures including age, race, sex, and immune status can also be important factors to consider when investigating human health.

For tick-borne diseases, and HME in particular, identifying the population that is susceptible to these diseases involves knowing how the population is structured and how 
this influences the spatial patterns of these diseases. Little, if any, evidence suggests a genetic susceptibility or resistance to HME (Lockhart et al. 1997; Paddock \& Childs 2003). Evidence does suggest that older populations and men are more susceptible to becoming infected with the HME causing pathogen (Paddock \& Childs 2003). This finding could be due to a number of reasons, but it may be linked to immune system status of older populations (Paddock \& Childs 2003). The fact that men are more susceptible than women may be due largely to behavioral factors.

\section{Behavior}

Human behavior is a very important factor to consider within the context of the ecology of human diseases. Our habits, movements, and perceptions often shape how diseases develop and spread within the human population (Meade \& Emch 2010). The transmission of diseases such as Ebola hemorrhagic fever in Central Africa has been found to be mostly due to burial practices by the loved ones of the deceased (Garrett 1994). With past Ebola epidemics, the disease was always spread to the caretakers of those who had been infected. This fact, as well as unsanitary conditions and equipment exacerbated the spread of this disease. Influenza is another disease that is spread from person to person due to close contact (Barry 2005).

With HME, behavior often determines how an individual comes in contact with the tick vector. Participating in outdoor activities such as hiking, or having an occupation involving working outdoors places these individuals in habitats favored by ticks (Paddock \& Childs 2003). Other behavior factors, such as using preventative measures 
against ticks, limit the risk of coming in contact with ticks, or limit the risk of a tick biting and potentially transmitting disease-causing pathogens.

Habitat

The habitat aspect of the human disease ecology triangle refers to both the built environment and the natural environment. Built environments are cities, towns, roads and other manmade structures. These are the places where people live and work. Much of our time is spent in this type of habitat (Meade \& Emch 2010). It is all too easy to consider this type of environment separate from the natural one, but in reality the natural environment is all around. A person's occupation and leisure activity often places him or her directly in the natural environment (Paddock \& Childs 2003).

The built and natural environments of and around humans must be considered when investigating diseases such as HME. Where people live and whether or not they have pets that go between indoors and out are particularly important factors to consider because of the ecology of the tick vectors and natural animal hosts. People who live in rural areas surrounded by wooded lands are more likely to be exposed to a greater density of the tick vector responsible for transmitting the HME pathogen. Likewise, those with pets that often venture in dense wooded or brushy lands and come inside are more likely to pick up ticks and bring them in the place of residence (Paddock \& Childs 2003; Meade \& Emch 2010). 


\section{Tick Habitats and Lifecycles}

The life cycle of most tick species consists of four stages, namely eggs, larval, nymph, and adult. Eggs are laid in the spring by adult females in leaf litter on the floor of deciduous forests. Emerging in late summer, the larval stage ticks search the forest floor for their first host to feed on. Typically these hosts range from small mammals to birds (STOP 2009; CDC 2010). During feeding, if the host is infected with a bacterial pathogen such as E. chaffeensis, the tick may also become infected (STOP 2009; CDC 2010). Once the ticks of the larval stage complete the first blood meal, they enter a dormant stage for the remainder of the fall and winter, and emerge the following spring as a nymph.

The next stage in the life cycle as a nymph is an important transition. Those that survive the winter emerge in the spring and early summer to search for their next host. If a tick that fed on an infected host of the previous year survives to feed on another vertebrate host, that tick may transmit the pathogen to its next host, infecting it as well. As a nymph, favored hosts consist of larger mammals, including other rodents, whitetailed deer, and humans (STOP 2009). The nymph stage, therefore, becomes the first stage in the lifecycle of the ticks that can potentially infect humans with a bacterial pathogen such as ehrlichiosis, since there has been no evidence of oviparous transmission (Lockhart et al. 1997).

The transition of nymphs to adults is less of an event than a process. During the months following their emergence, the surviving nymphs gradually become larger, and by the fall are considered to be mature adults (STOP 2009). Mating between male and female A. americanum adults occur in the fall once both have taken a final blood meal. 


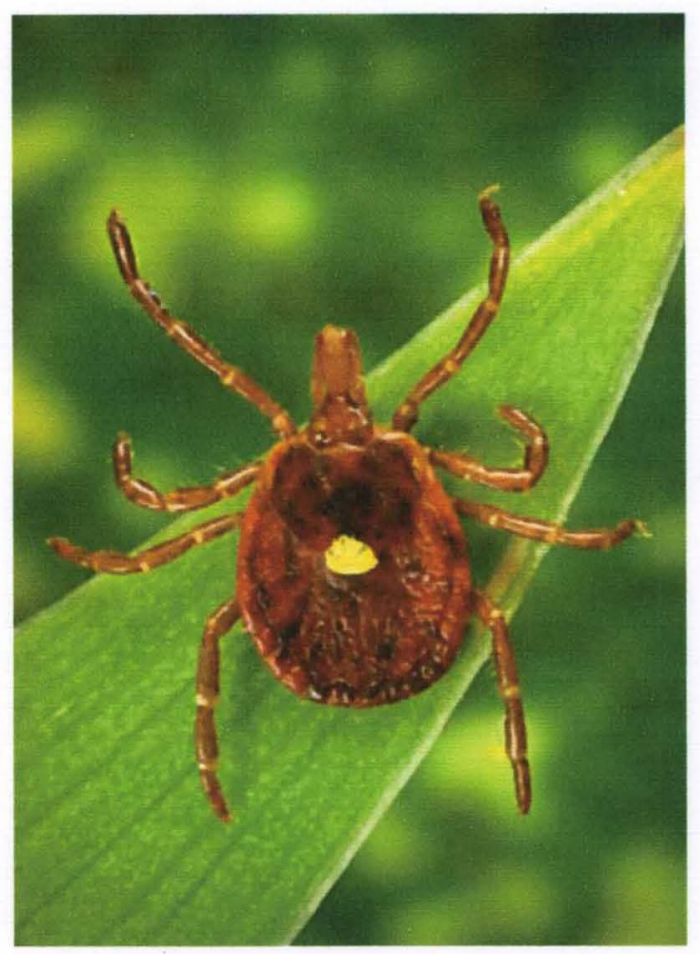

Figure 2. Lone star tick (Source: Center for Biosecurity of UPMC)

Shortly after mating, the males die, and the females remain on the forest floor during the winter months. As temperatures drop below $40{ }^{\circ} \mathrm{F}$, the female becomes dormant. In the following spring, she will lay thousands of eggs (CDC 2010), thus completing the life cycle. Figure 2 shows a photograph of this tick species.

With more people becoming active in outdoor activities that place them directly in tick habitats, the importance of understanding where people may be at increased risk is now greater than ever. The peak times of tick activity are also some of the peak times that people take advantage of warmer weather. Hiking, mountain biking, early season hunting and fishing, and even some occupations put people in the same brushy wooded habitats that are favored by many species of ticks, especially the lone star. In Missouri, 
HME is one of the most prevalent tick-borne diseases in the state, and how aware people are of their risk of coming in contact with ticks is an important factor to consider.

\section{HME and Other Tick-borne Diseases in Missouri}

\section{HME}

Currently, the CDC places the distribution of the lone star tick, the vector responsible for the transmission of HME and tularemia, in the south central and southeastern United States, including Missouri. Several factors play significant roles in the distribution of the lone star tick, and there has been a considerable amount of research on the tick's habitat (Yabsley et al. 2005; Wimberly et al. 2007; Stein et al. 2008).

Yabsley et al. (2005) provided a spatial analysis of the distribution of $E$. chaffeensis by assessing the white-tailed deer (Odocoileus virginianus) population densities throughout the endemic region of the country. White-tailed deer are important primary reservoirs for E. chaffeensis (Lockhart et al. 1997; Yabsley et al. 2005; CDC 2010), and high white-tailed deer density has been demonstrated to be linked to high densities of lone star ticks and E. chaffeensis prevalence (Yabsley et al. 2005). By utilizing several geospatial modeling techniques and incorporating serological testing of 563 deer, Yabsley et al. demonstrated that several climatic and land cover variables, including elevation, percent mixed deciduous forest, wooded wetlands, and summer maximum temperature, were useful in the prediction of $E$. chaffeensis distribution.

In addition, the authors showed that several subregions exhibit disparate indicative variables for the presence of the Ehrlichia bacterium. For instance, while the eastern sub-region of Virginia, North and South Carolina, Georgia, Tennessee and 
Kentucky have predictive variables consisting of elevation, percent forest cover, and soil types, the western sub-region (Texas, Oklahoma, Kansas and Missouri) show only precipitation and summer minimum temperature as predictive variables. Missouri's landscape of deciduous and mixed forests and optimal precipitation offer a favorable habitat for ticks, especially the lone star tick.

\section{Other Common Tick-borne Diseases}

While HME is the most prevalent newly-emerging tick-borne disease in Missouri, it is certainly not the only one (CDC 2011). Other diseases spread by ticks are found in this region and need to be considered when investigating overall knowledge of tick-borne diseases residents have. The inclusion of Lyme disease, Rocky Mountain spotted fever, and tularemia questions asked to Missouri residents is to elucidate not only how aware these residents are of tick-borne diseases, but also how aware they are of these types of diseases that are in their own back yard.

Lyme disease is the most common vector-borne disease in the United States (Guerra et al. 2002; CDC 2011). Spread by the blacklegged tick Ixodes scapularis, this disease is most common in the northern Midwest states of Wisconsin and Illinois, and along the New England coastal area (CDC 2011). Lyme disease and its arachnid vector are not common in Missouri, and only few cases have been reported in this region. In 2009 only three confirmed Lyme disease cases were reported in Missouri (CDC 2011c).

Rocky Mountain spotted fever is another common tick-borne disease in the United States and other parts of North and South America. It was first discovered to be a tick-borne disease in 1899 and since then has become extremely common in North and 
South Carolina, Tennessee, and Missouri (Thorner et al. 1998; CDC 2011). In 2009 there were a total of 253 confirmed or probable cases of Rocky Mountain spotted fever in Missouri (CDC 2011).

Tularemia is a bacterial disease that is spread to its host in multiple ways, including by the bites of ticks. In the U.S., most reported cases occur in the central part of the country, primarily around Missouri and Arkansas (CDC 2011). There were 13 cases of tularemia reported in Missouri in 2009 (CDC 2011c).

\section{HME Research and GIS applications}

Since its emergence out of the central part of the U.S. in the late 1980s, the foci of HME research include the emergence of the bacterial pathogen itself and the relationship between tick vector and the pathogen (Paddock \& Childs 2003; Randolph 2004), the role white-tailed deer play as the primary natural reservoir hosts for the Ehrlichia bacterium (Lockhart et al. 1997), and the geographical distribution of ticks, habitats, and at risk areas.

An understanding of the geographical distribution of the vectors responsible for the transmission of diseases is critical in identifying at-risk populations. Many of these involve the application of Geographic Information Systems (GIS) for spatial analysis and mapping. For tick-borne diseases, studies have been done on tick habitat suitability (Guerra et al. 2002), vector mapping and prediction (Stein et al. 2008; Keefe et al. 2009), and risk mapping (Guerra et al. 2002; Yabsley et al. 2005; Wimberly et al. 2008a; Wimberly et al. 2008b;), and are imperative for identifying key regions and locations where people may become exposed to ticks. These models are irrefutably important in 
identifying regions that contain high densities of ticks, and therefore where people are likely to come into contact with them. However they do not consider who may come into contact with ticks and why.

Research utilizing GIS modeling for HME is limited, and those that have investigated this disease have looked at environmental and climate variables to help explain the distribution of reported cases of the disease. The two key research articles mentioned (Yabsley et al. 2005; Wimberly et al. 2008b) found that ecological variables such as deciduous forest mix and other forest coverage, wooded wetlands, soil type, humidity, precipitation, among others, were important statistically significant predictor variables in creating risk maps of HME in South-central U.S (Figure 3).

Yabsley et al. (2005) used deer serology data collected in specified counties across the South-central region of the U.S. With serological analysis, the researchers were able to determine whether or not the bacterial Ehrlichia pathogen was established in the deer population, and therefore have an idea of the pathogen's geographic distribution (Lockhart et al. 1997; Yabsley et al. 2005). Through the use of the geostatistical method of kriging, Yabsley et al. were able to create another risk map based on the assumption that counties close to other counties with positive deer serological results would be more likely to also have the pathogen established in the region.

Both the GIS analysis and geostatistical modeling for HME provided accurate predictability of actual reported cases of HME in the South-central region of the U.S. The sensitivity of these tests, or the likelihood of predicting high incidence of the disease in areas of actual high incidence, was very high. However, the specificity of each analysis, or the ability to correctly classify regions of low or no reported cases of HME, 
fell significantly. Specifically, the entire state Missouri was predicted to have high endemic rates of HME in both the GIS and geostatistical modeling. Reviewing actual cases reported to the CDC shows that endemic rates across Missouri are not as ubiquitous as these models suggest.

This research project is a way to enhance some of the GIS-based research of HME spatial distribution, primarily the studies conducted by Yabsley et al. (2005) and Wimberly et al. (2008b). While GIS analysis must continually be incorporated in investigating vector-borne diseases and HME alike, other methods that include residential awareness and susceptibility must also be taken into account.

\section{Current Trends in Medical Geography}

Within the past two decades there has been a growing recognition by many medical and social geographers of the need to incorporate the individual human experiences to further understand health spatial patterns. These experiences include sense of place and how people perceive their surrounding environment and the implications they have on their health (Mayer 1992; Mayer 1994; Litva \& Eyles 1995; Mayer 1996; Philip 1998; Dyck 1999; Kearns \& Moon 2002; Zimmerer 2007; Smyth 2008; King 2010). In recent years, the positivism and empiricism that have embraced quantitative modeling and GIS analysis have been supplemented and even challenged by other epistemologies that consider the more human elements of medical geography (Gregory et al. 2009). 


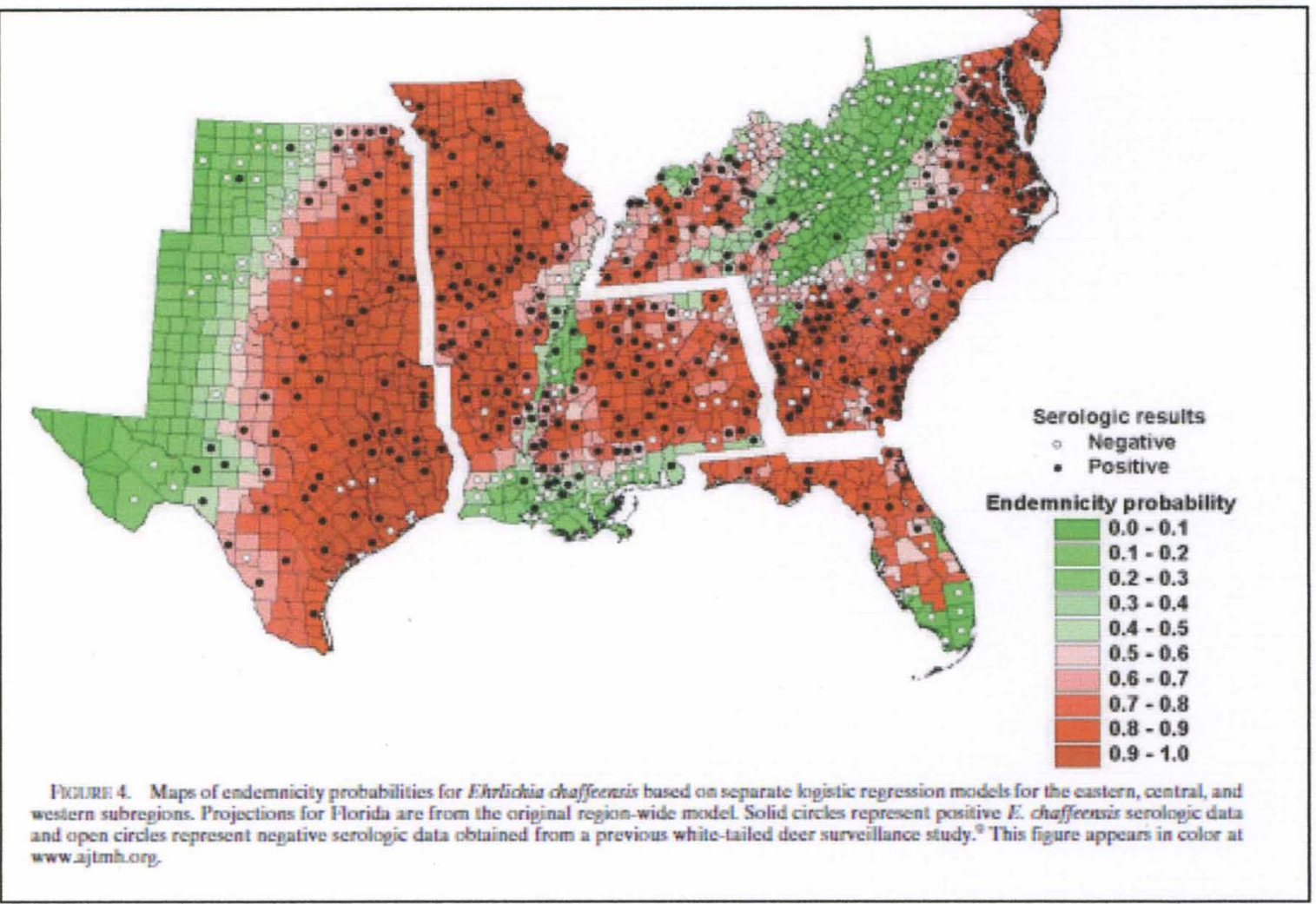

Figure 3. Modeled risk associated with ecological variables related to preferred tick habitats. (Source: Yabsley et al. 2005, Figure 4, pg. 846).

In particular, humanism has focused on describing the perception of place and one's experience with the surrounding environment (Gesler et al. 2009). Within the framework of these more human elements, the attempt of this project is to eliminate the binary relationship that seems to exist between researcher and the human subjects being researched and include the social aspect of diseases.

The aim of the numerous GIS studies mentioned is to identify disease hot spots, or clusters, or to attempt to model predictive habitat locations based on favored tick habitats. These studies do not take into account the ever changing-variable of human behavior. To further understand the observed spatial patterns of HME requires an 
assessment of human perceptions of these diseases. To understand these perceptions, this study includes the use of the HBM. Infused within this model is the theoretical framework of human perception of health, including awareness, perceived susceptibility, severity, and benefits of preventative measures.

\section{Health Belief Model}

The Health Belief Model (HBM) is a theoretical model developed by the U.S. Public Health Service in the 1950 s to explain health related behavior that is pertinent to awareness and perceptions of individuals (Glanz \& Rimer 1997; Last 1998; Butterworth et al. 2010). The HBM was developed in order to better understand why people were not participating in free health exam services. This same concept can be applied to this research by addressing the questions that are considered in this model regarding HME and other tick-borne diseases. The HBM can be thought of as an assessment of overall perceptions of individuals regarding their own health and health risks. These perceptions include:

Perceived susceptibility - Do people believe they are susceptible to HME or other tick-borne diseases?

Perceived severity - How seriously do people take this disease threat?

Perceived benefits - Do people believe that the preventative strategies help prevent contracting the disease?

Perceived barriers - Do the benefits out-weigh the costs? 
Cue to action - What education and information is available on these diseases that reminds and prompts people of the importance of using these preventative strategies?

Self efficacy - Are people confident in these strategies and in using them? Applying this model to this investigation of overall awareness and perceived threat of HME and other tick-borne diseases requires conducting qualitative analysis at an individual level. These concepts were considered in the designing of the questions of the data collection survey instrument (see Appendix A).

\section{Surveys}

In 2008 , Gould et al. published a study that utilized a telephone questionnaire that measured descriptive factors of Lyme disease in Connecticut. The questions respondents were asked ranged from diagnosis of Lyme disease in the previous year, knowledge about the risk of getting Lyme disease, and the protective behaviors and other tick preventative controls used. In addition, respondents were asked about their level of knowledge of Lyme disease, how much of a problem it is where they lived and what they thought their likelihood of becoming infected with Lyme was (Gould et al. 2008). This study is one of the few that have attempted to measure behavior and knowledge of tick-borne diseases, and it has made an important contribution to the development of other methodologies.

Similarly, Butterworth et al. (2010) used surveys to investigate overall knowledge, awareness and perceived risks of mosquito-borne diseases in southwestern Virginia. The aim of this study was to determine how individual residents of Virginia perceived their personal risks of diseases spread by mosquitoes and how aware they were 
of the risks involved. The survey tool used the theory of the HBM framework. Other studies have dealt with understanding the perceived risk and awareness associated with Lyme disease (Herrington 2004; Herrington et al. 1997).

An important consideration for this study was how to administer a survey to obtain data from residents of Missouri. Much work has been done on the administration of surveys of health related research (i.e. Holt 2010; Addington-Hall et al. 1998; Leeuw et al. 1996; Sibbald et al. 1994). In these applied studies the researcher bias and respondent interaction is considered. Response rate is also an important factor to consider. Receiving completed surveys from respondents has important implications about how well the population of each study location is represented (Parker \& Dewey 2000; Krysan et al. 1994). The available research suggests that the face-to-face methods work best to reduce bias and increase response rate (Bowling 2005).

\section{Conclusion}

The integration of human perceptions and awareness of HME and other tickborne diseases with spatial analysis allows for a deeper understanding of the distribution of this disease. An important reason for the observed disparities between predicted risk mapping and actual reported HME cases may be due to the differences in overall awareness of tick borne diseases by residents and their perception of these risks and the efficacy of precautionary measures (Gould et al. 2008).

Significant disparate responses between those who live in counties with high incidence of HME compared with those who live in counties with low incidence in regards to protective measures used, or overall tick knowledge may indicate that 
locations with high incidence of reported HME cases have little or no tick educational material in outdoor public areas, or that numerous people reside in rural regions. On the other hand, if the results are reversed, it may indicate that cases in high incidence areas are due to the growing recognition of this disease and that people are more likely to go to the clinic when they become symptomatic.

The available literature on HME and related tick-borne diseases focuses on the relationship between the environment and the tick-borne diseases. Other literature on HME focuses on the clinical research on the biology and genetics of the Ehrlichia pathogen and how it causes diseases in humans. There is a gap in the literature on understanding the human and environment relationship and how people perceive their risk of contracting a tick-borne disease such as HME. Related studies that have been done to investigate this human-environment relationship have done so with mosquitoborne diseases (Butterworth et al. 2010) and Lyme disease in the endemic region of that tick-borne disease (Gould et al. 2008; Herrington 2004; Herrington et al. 1997). There have been few or no studies done to investigate the relationship between people and their environment that consider the perceived risks of HME.

Furthermore, while both Butterworth et al. and Gould et al. investigate using surveys on an individual level, neither includes feedback from the residents themselves that further explains their answers for the survey. This research project includes methods that allow respondents to answer questions through a series of open-ended questions as well as closed-ended questions. Finally, little or no research in vector-borne diseases has used the approach of surveys or questionnaires to link GIS analyses and modeling to 
awareness and susceptibility in an effort to further understand the spatial patterns modeled and observed for these diseases. 


\section{CHAPTER III}

\section{RESEARCH METHODS}

\section{Study Areas}

The four study counties of Ralls, Macon, Carter and Douglas were chosen in the state of Missouri. All were modeled as having high endemic probabilities of Human Monocytic Ehrlichiosis (HME) based on the regional risk maps developed (Yabsley et al. 2005; Wimberly et al. 2008b). To determine actual case data, the number of reported cases from the Centers for Disease Control and Prevention were derived for the years 2005-2009.

HME incidence data for the years between 2005 and 2009 helped identify key study counties where the reported incidence of the disease was largely consistent through the five years (Figure 4). Four study counties were chosen. Two are known to have consistently high numbers of confirmed cases of HME (Macon and Carter Counties), while two are known to have a consistently low number of cases reported between 2005 and 2009 (Ralls and Douglas Counties), even though GIS modeling indicated that they were high risk counties (CDC 2007, 2008, 2009, 2010, 2011b). The four study counties are shown in Figure 5. 


\section{Average Annual Incidence of $\mathrm{HME}$ 2005-2009}

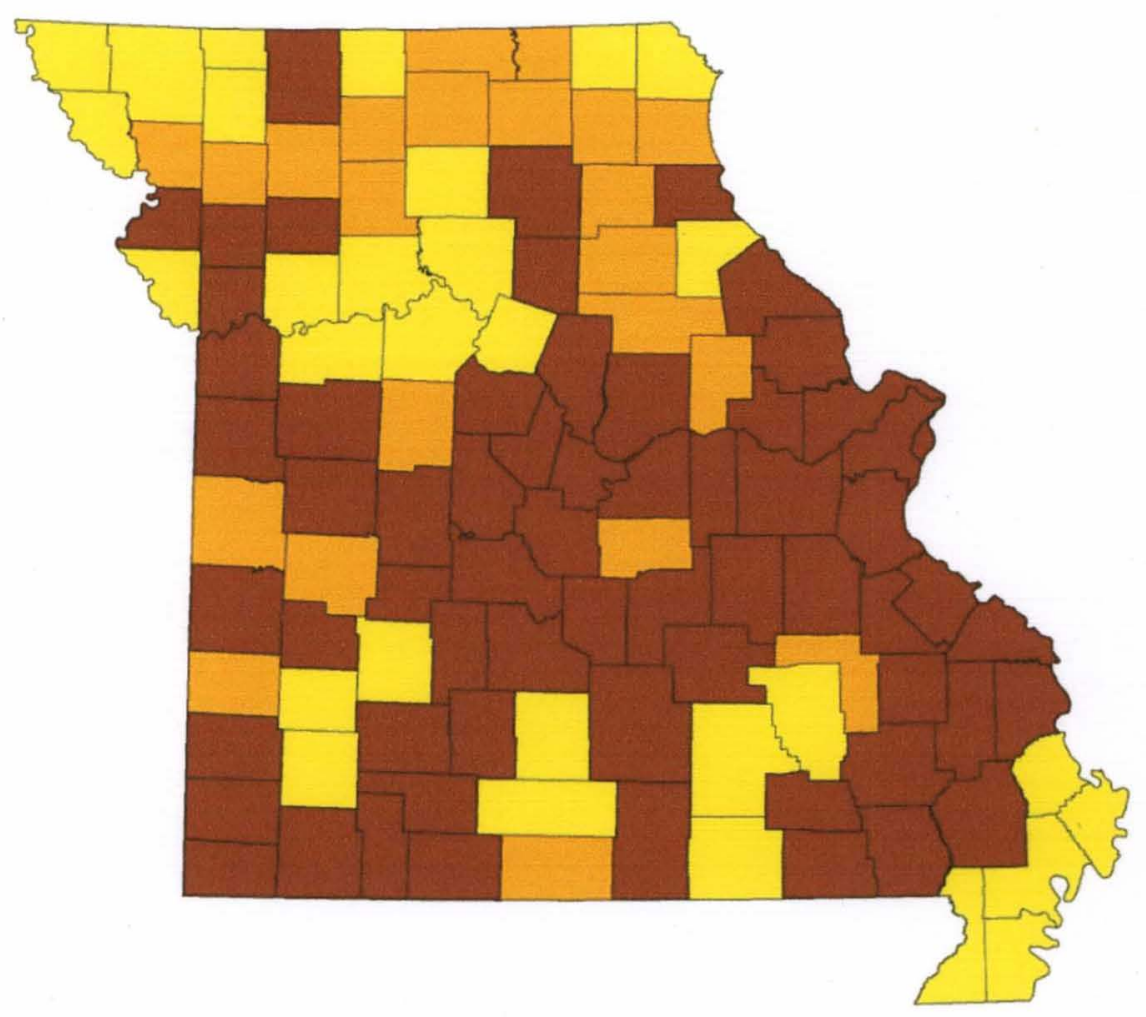

Incidence

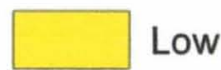

Medium

High

Figure 4. Average annual incidence of HME in Missouri between the years 2005 and 2009. (Source: Centers for Disease Control and Prevention). 


\section{Study Locations}

Macon County
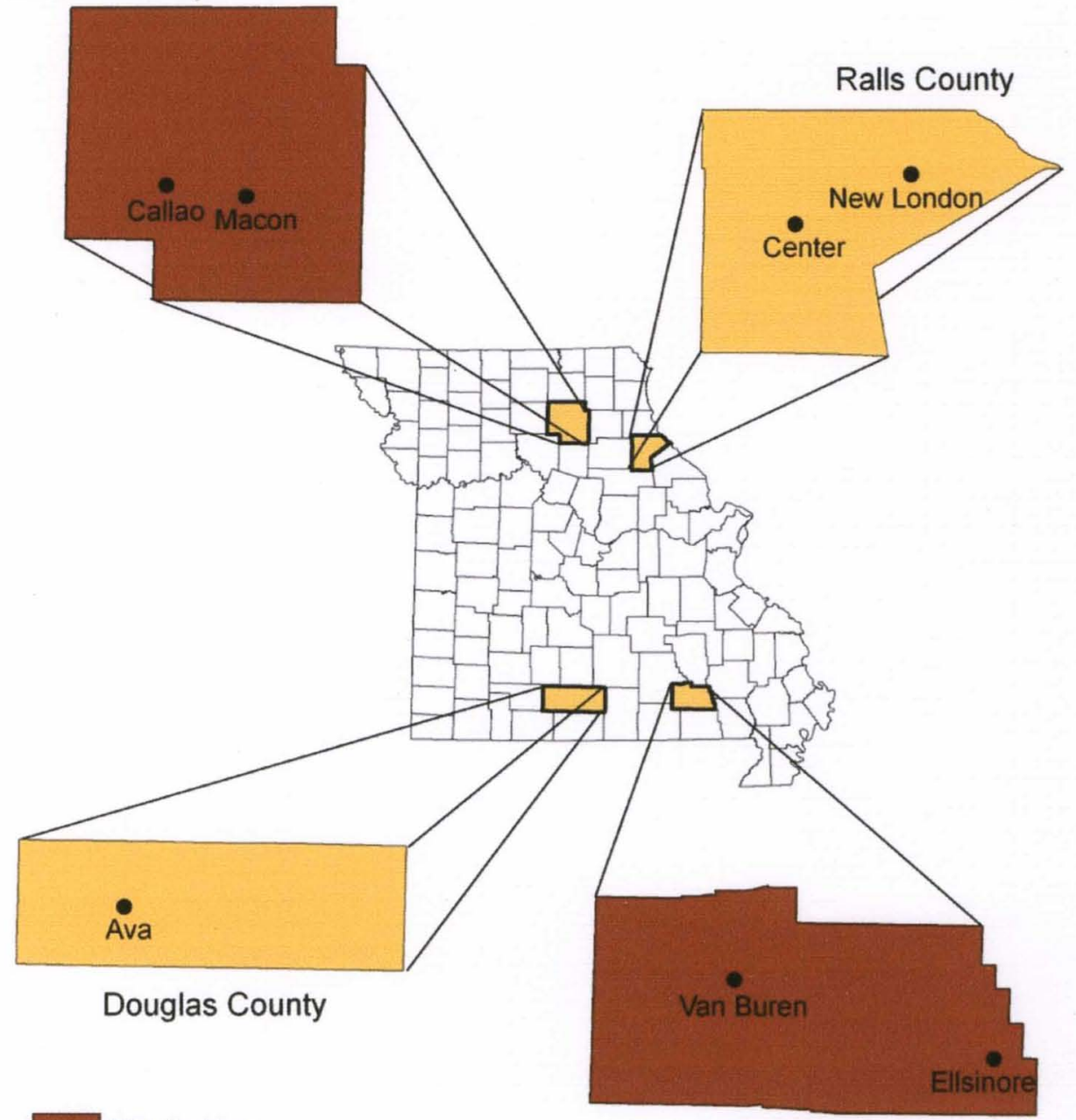

High incidence

Low incidence

Carter County

Figure 5. Study counties of Ralls, Macon, Douglas and Carter were chosen for this project. Within each study county were chosen sites where surveys were distributed. These locations are main population centers where post offices were located. 

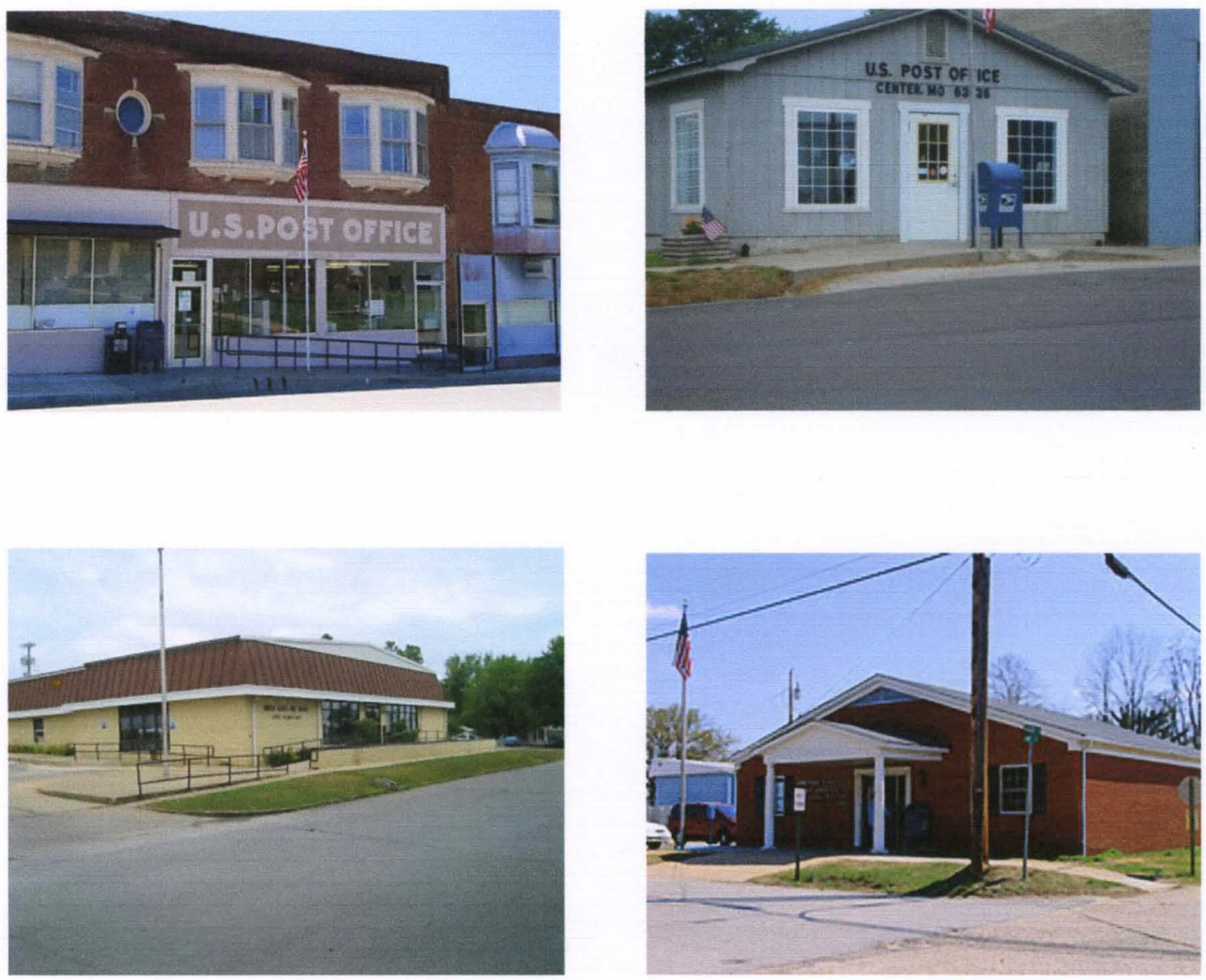

Figure 6. Four of the seven post office locations visited where surveys were distributed during this research project. From top left and clockwise: New London, Ralls County; Center, Ralls County; Van Buren, Carter County; Macon, Macon County.

Within each of these counties, study sites were chosen based on their being main community centers and a high population representation (Butterworth et al. 2010). These locations have services and facilities such as grocery stores and other shopping centers, businesses, and U.S. post offices, which attract individuals from surrounding rural areas of the county. Following the survey methods used by Butterworth et al. (2010), individuals in this study were asked to participate in filling out a survey at one of the seven study area post offices (Figure 6). Post office locations were chosen because they 
provide a convenient access to a large population size and offer the opportunity to obtain information from a diverse sample in a public setting (Butterworth et al. 2010).

Since the focus of this study is on tick diseases, seasonal constraints required this study to be conducted during the peak times of tick activity, which are in the late spring and summer months (Paddock \& Childs 2003; CDC 2011a). The primary reason for this is to ensure that when respondents were asked questions regarding tick diseases, they were in more of a mindset of awareness and education while preventative practices are more likely to be implemented (Butterworth et al. 2010).

Surveys were distributed to residents of the chosen study counties during the last week of July and first week of August, 2011. The amount of time spent collecting data from the residents of each of the study sites was equally considered for all study locations. The study sites within each of the study counties were visited during the hours of operation of the post office and the researcher remained at each post office location for one full business day. This was to provide opportunities for people of all schedules to participate in this research project. Those who chose to participate had the opportunity to take part in the project by filling out the survey alongside the researcher or taking it inside the post office with them. Respondents were not compensated for their participation.

\section{The Survey}

The survey for this study used components of the Health Belief Model (HBM) which was developed by the U.S. Public Health Services in the 1950s (Glanz \& Rimer 1997; Butterworth et al. 2010) (See Appendix A). The HBM is a theoretical model to 
explain health related behavior that is pertinent to awareness and perceived risk of health threats (Last 1998). For this study, three main aspects of the HBM used in the development of the survey tool were centered on the awareness of tick diseases and included perceived susceptibility, perceived severity of HME and other tick-borne diseases, and perceived benefits of preventative practices of residents in Missouri. These components were evaluated through a series of short, direct questions answered by individual respondents. In addition, the open-ended question of the types of education and information that is available or that should be available addresses the component of the model of cue to action, which considers the exposure to the pertinent information that is or should be available regarding ticks and the diseases they spread.

The survey questions addressed overall knowledge of HME and other tick-borne diseases; perceived susceptibility and severity of these diseases; potential at-risk behaviors, such as frequently hiking in the woods; types of residential, occupational, and leisure environments the respondents are exposed to; length of residency; how often ticks were found in the place of residence; as well as any involvement in outdoor activities that may have put individuals at a greater risk of acquiring tick diseases. Most questions were closed-type questions, which means respondents were only required to check a box that applied to their answer. The answer choices consisted of a yes/no choice as well as an inclusion of the Likert scale answers that asked respondents to rate certain questions such as how concerned one is about tick-borne diseases ranging from very concerned to not at all. These questions were designed to optimize accuracy, shorten the time it took to take the survey, and provide the researcher with basic information for coding procedures. 
Some questions, such as how residents were aware of the tick diseases in their area if they chose 'yes' for being aware, particular outdoor activities engaged in, and thoughts on the types of education that should be available, were asked as open-ended questions. These questions were designed to identify key information and themes developed from individual residents while minimizing influence of shaping answers from the researcher. In addition, basic demographic information such as age, race, and education was considered. No question of the survey asked the respondent his/her name or actual address, and once obtained all information was coded.

Through the analysis of the available literature that uses surveys in public health research applications, face-to-face method of administration was shown to be have the best results overall. Compared with telephone interviews, self-administered and postal surveys, and electronic surveys, face-to-face administration of short surveys has been shown to provide a more complete coverage of the population, as well as high survey response with no follow up methods necessary, more completed portions of the survey, and has been shown to be the preferred mode of administration (Bowling 2005). An additional benefit of face-to-face administration is that it provided the opportunity to clarify any misunderstandings, and ensured the respondent fully understood the purpose of each question, which would not have been possible through other disconnected methods.

\section{Respondents}

For each study county, any resident of that county over the age of 18 was eligible to participate in this study. Respondents were approached as they entered the respective 
post office of each study county and briefed on this project, including an explanation of the significance of the study and how it might be important to them (Butterworth 2010). They were then asked if they would like to participate. Afterward respondents gave their verbal consent after reviewing the written preamble of the project approved by the Institutional Review Board (IRB) (See Appendix C). Participating respondents had the opportunity to fill out the survey alongside the researcher, or to take it inside. The survey took about three to five minutes to fill out. All questions on the survey were optional, and the respondent could decide to discontinue participating at any time.

\section{Data Analysis}

The analysis of the data collected involved two processes that included statistical analysis and discourse analysis of the written responses. The statistical analyses included the use of the SPSS statistical software to determine any significant differences between counties of high incidence of HME compared with counties of low incidence of HME, and to identify the relationship between overall knowledge of tick diseases and HME and high/low rate counties. Variables of interest for this analysis in particular were overall awareness, whether or not residents used preventative strategies, how effective they found those strategies, how concerned they are about coming in contact with ticks and contracting a tick-borne disease, and how likely they are to receive medical help if they became symptomatic after finding an attached tick. The use of SPSS software allowed for the analysis of these variables and to determine if any relationships exist among them and the observed spatial patterns of reported HME cases. 
Overall awareness was measured in two ways. The first method of measuring was coding the answers of the survey for each question by signifying a 1 for those who answered yes and a 0 for those who chose no (Butterworth et al. 2010). These binary data were coded for each of the awareness related questions, including awareness of tickborne diseases in Missouri, tick-borne diseases in the immediate region, and awareness of each of the specific types of diseases (ehrlichiosis, Lyme disease, Rocky Mountain spotted fever, and tularemia). The second method of measuring awareness for the analysis was scoring the overall awareness. This included summing each of the answers for each of the six questions regarding tick-borne disease awareness. If a person answered 'yes' for all of the questions, their overall awareness score was a 6 . If another respondent indicated they were not aware and chose 'no' for all of the questions, their score was a 0 (Butterworth et al. 2010).

Similarly, measuring the concern of residents for coming in contact with ticks and contracting a tick-borne disease were first considered separately. The answers for each of the two questions regarding concern were in interval format, with a grade from the Likert scale ranging from not at all concerned to very concerned, with four total choices. Coding the answers for these questions included scoring an answer of 'very' with a 4 and an answer of 'not at all' with a 1 . The overall score for concern took the sum of the coded answers to these two questions, with the highest score possible as 8 , for highest concern for both questions.

Coding the answers of the survey for measuring the effectiveness of preventative measures recommended by the $\mathrm{CDC}$ was done in a similar manner as for awareness and concern. The interval answer data were coded as a 4 for very effective and a 1 for not at 
all effective for each of the preventative measures. The overall score for effectiveness used the sum of all four specific preventative methods, with the highest score of 16 representing a respondent who considered all four methods very effective.

The first part of the statistical analysis used two independent t-tests of the means. This analysis provided a means of analyzing any significant differences in the observed mean of the coded answers of awareness, concern, effectiveness, and seeking medical help between study counties of Missouri with high and low reported cases of HME. In this way it can be determined if locations in counties with high incidence versus low incidence of HME have any significant differences between them (Norušis 2008). The two independent samples included the survey mean of the total awareness, concern, and effectiveness scored answers for counties of high reported cases of HME cases in one category and counties of low HME cases in the other category. SPSS statistical analysis software was used to calculate significant differences between the two independent samples at a significance of $\alpha=0.05$.

Multiple linear regressions were used to determine any predictability of respondents' demographic, environmental and behavioral information to overall awareness, overall concern, and overall effectiveness of preventative measures. Information collected on gender, age, and education were used as independent variables, as well as variables including yard classification from treeless to heavily wooded, frequency of finding ticks, and use of preventative methods. Ethnicity was excluded from this analysis because most people indicated they were white. This analysis was to determine if there was any significant relationship between a person's individual background and his/her awareness of and concern for tick-borne diseases and overall 
effectiveness of the preventative methods (Norušis 2008; Butterworth et al. 2010). Variables were considered significant at $\alpha=0.05$. To address missing data from the surveys, listwise deletion of the variables was used and the results listed are from this analysis. Because a large number of people did not fill out income, this variable was excluded from the analysis all together (Norušis 2008).

Another component of this research was to determine any differences between people who use preventative measures and people who do not. The independent variables for each of the analyses included the frequency of individuals finding ticks on themselves, family members or pets, classification of individual yards; length of residency in the study county; and how likely the individuals are to receive medical help if they became symptomatic. This method determined if there were any significant difference among all individuals in all four study counties and their likelihood of using preventative measures against ticks.

Discriminant analysis was used to identify any significant differences between populations who use preventative methods and answered 'yes' on the survey and those who answered 'no' (Norušis 2008). Respondents who indicated they used preventative measures were scored a 1 , while those who indicated they did not were scored as 0 . To deal with missing data, both the listwise missing-value treatment option and the elimination of the income variable were considered. Discriminant analysis is a helpful way to determine significant differences between classified categories (Norušis 2008), and has been used in geospatial research of important differences in ecological land cover types (Lobo 1997; Guo et al. 2003), environmental health related research such as 
differentiating between two pollution sources (Parveen et al. 1999) and vector-borne diseases (Guerra et al. 2002), and can be applied to this research.

Analyzing the open-ended questions of the survey required a different approach to evaluate the responses. These questions offer the participants a way to respond without the boxed-in answer choices closed questions have and allow them to go into more detail than a closed-type question allows for. It has been shown that open-ended questions can provide valuable insight into understanding populations more thoroughly than simply using closed-ended type questions (Niedomysl \& Malmberg 2009). To analyze the responses of these questions requires considering each of these written responses separately and organizing the responses by developing themes and ideas.

Each survey was reviewed and answers to these questions were considered and analyzed through discourse analysis for their implications for this research project. Discourse analysis is a means of analyzing the writings and language of respondents that helps unveil the meaning of their written responses. The goal of analyzing these written responses through this method was to understand through the respondents themselves how their knowledge may or may not be linked through informed decision-making in regards to tick-borne diseases (Cheek 2004; Starks \& Trinidad 2007).

Discourse analysis involves understanding the meaning behind language by analyzing verbal or written responses in the context of relationships and activities (Starks $\&$ Trinidad 2007). This method was applied to this study because it offers a way to understand how people perceive their relationship with their surroundings through their written responses to the selected questions on the survey instrument. Specifically this method applies the how people use language to respond to the questions of the survey. 
These can be related to their personal background, including level of education, as well as level of awareness of environmental relationships with ticks and tick-borne diseases.

Within the context of discourse analysis, one objective was to identify the important themes produced by residents, if any, that could or should be investigated further, while identifying important factors that may initially be unknown to the researcher and existing literature. Specific themes that may have important implications are how residents are aware of tick-borne diseases, specific outdoor activities that put populations at risk, and education practices that are available or that should be enforced or implemented. Issues brought up by the residents provide an important perspective of how they perceive their own risk along with the available information on tick-borne diseases; whether or not they feel at risk, identify methods of distributing information more efficiently, along with many other possibilities.

\section{Hypotheses}

Contact with the tick vector is necessary for the transmission of the pathogen responsible for HME. With GIS risk mapping, these models do not consider the relationship people have with the outdoors and when people may come in contact with ticks. They also do not consider residential awareness residents have and what, if any, preventative practices are used. Because of this, residential awareness is hypothesized to have an imperative influence on the observed spatial pattern of reported HME. Of the four study counties, the residents of the two that are classified as high incident with low actual reported cases (Ralls and Douglas Counties) are hypothesized to have higher awareness of tick diseases in their local areas, and more likely to practice preventative 
strategies against ticks than the counties with actual high incidence of reported HME cases (Carter and Macon Counties). In addition, residents of Ralls and Douglas Counties are hypothesized to be more concerned with coming in contact with ticks, and more concerned about contracting a tick-borne disease than residents in Carter and Macon Counties, and more likely to receive medical help if they become symptomatic after finding a tick attached.

Furthermore, through the existing literature that has investigated similar questions (Herrington et al. 1997; Herrington 2004; Butterworth et al. 2010) age, gender, higher education, and income are expected to be important demographic and socio-economic variables related to overall awareness of the risks associated with ticks. Additionally, age is predicted to be a significant variable in relation to the use of preventative methods and the overall effectiveness of the recommended strategies to protect against ticks. Where residents live, with respect to urban and rural environments, is also predicted to be an important variable. Those who live in rural areas are predicted to be less aware and concerned because of a disconnection that might exist living away from nearby cities or towns. The frequency of finding ticks is also predicted to be an important factor in the overall awareness and concern.

Analysis of the open-ended questions of the surveys may yield unpredicted results. The purpose of these questions is to identify key information from residents without influence from the researcher as well as identify information that the researcher may initially be unaware of. Initial expectations for these questions are that people may be aware of these diseases through a wide array of sources such as the news on television or in newspapers, knowing someone who has had a tick disease, or other unknown 
potential sources. Should clustering of a common theme or idea result across much of the study population, such as common outdoor activities that residents take part in, local education and raising awareness campaigns that are available or should be available, as well as others, these may be addressed and determined as important considerations to further investigate for future research. 


\section{CHAPTER IV}

\section{RESULTS}

\section{Survey Response}

A total of 296 individuals were approached in all four study counties, with 185 choosing to participate, yielding an overall response rate of $63 \%$. Forty-five individuals participated in Carter County, 44 in Douglas County, 51 in Macon County, and 45 in Ralls County with a response rate of $56.9 \%, 65.6 \%, 66.2 \%$, and $61.6 \%$, respectively. The general make up of the respondents is provided in Table 1. Of the individuals who chose not to participate in the study, 82 said they were too busy, seven said they were on the job or on their lunch break, seven said they were not actual residents of the county and therefore could not participate, and 15 said they were either not interested or gave no reason.

\section{Analysis of Differences}

Two independent sample t-tests of the mean were used to determine any significant differences between populations in high/low incidence counties survey responses regarding awareness, concern, and effectiveness of preventative methods against tick-borne diseases. All variables were not found to be significant at $\alpha=0.05$, which lead to accepting the null hypothesis awareness, concern, and effectiveness do not 
differ between high/low regions. To examine the results further, overall results of the sum of the survey scores of overall awareness, overall concern, and overall effectiveness were broken down to the main components as they were asked on the survey to determine if any difference existed (Table 2). The results show that residential awareness of tick diseases in Missouri is suggestively different between high/low regions with a significance at $\alpha=0.10$.

\section{Awareness}

When respondents were asked about their awareness of tick-borne diseases in Missouri, 167(90\%) marked 'yes' on the survey, indicating they were aware of these types of diseases. When asked if they were aware of these tick diseases in their region, 132 (71\%) indicated they were aware. For each specific tick-borne disease, 35(19\%) were aware of Human Monocytic Ehrlichiosis (HME), 174 (94\%) were aware of Lyme disease, $152(82 \%)$ were aware of Rocky Mountain spotted fever, and $26(14 \%)$ were aware of tularemia (see Appendix B for complete survey results).

The awareness, measured by residents who selected yes, of tick-borne diseases in Missouri for the specific counties of Carter, Douglas, Macon and Ralls was $36(80 \%), 41$ (93\%), 47 (92\%), and 43 (96\%), respectively. Awareness of tick-borne diseases for residents in their immediate region of Carter, Douglas, Macon and Ralls Counties was 30 (66\%), $32(73 \%), 37(72 \%)$, and $33(73 \%)$, respectively. Figure 6 shows the relationship

of awareness of each tick disease asked on the survey against actual reported cases of that disease for the year 2009 . 
Table 1. Survey Respondents

Total approached: 296

Total Responses: $185(63 \%)$

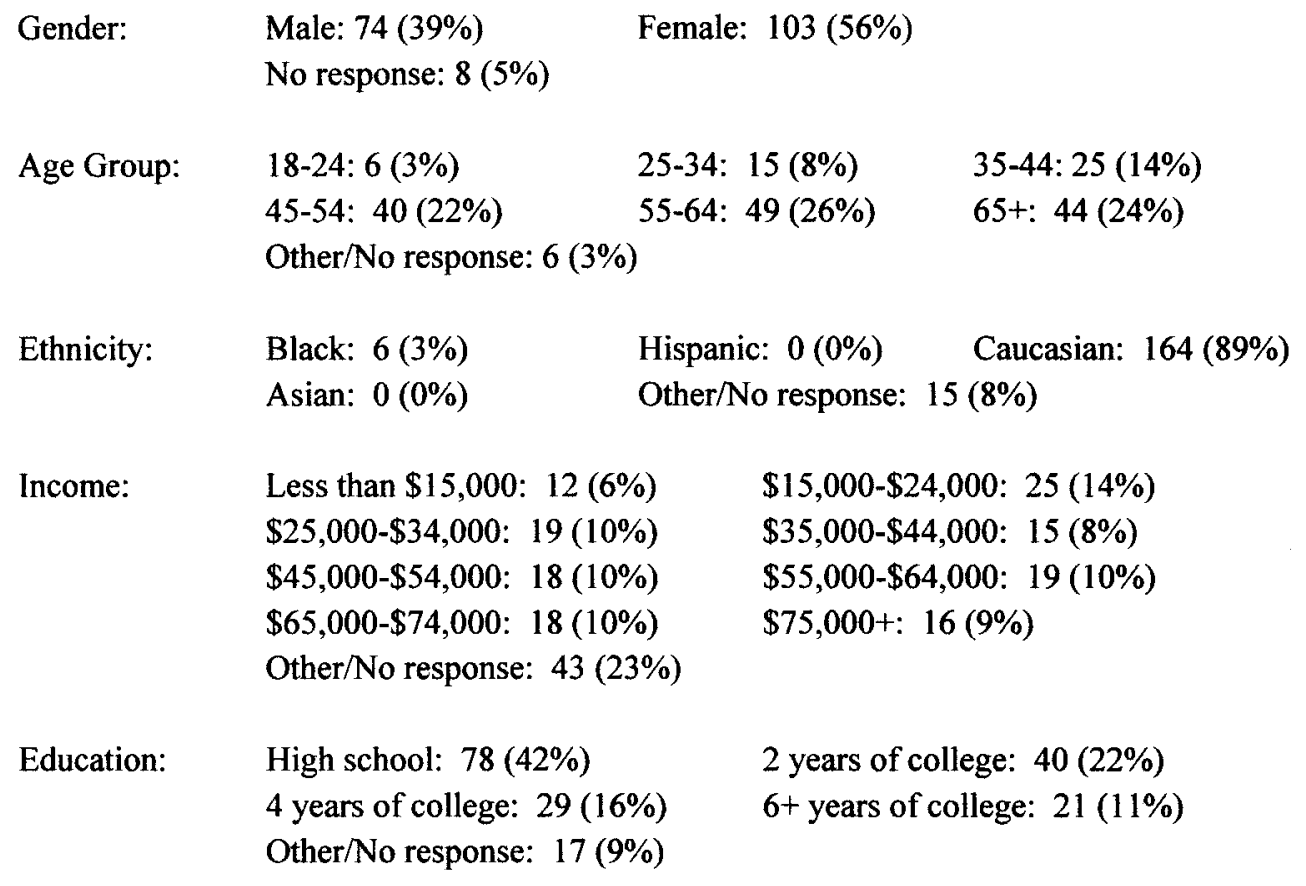


Table 2. Results of Two Independent Samples t-test

\begin{tabular}{|c|c|c|c|c|c|c|c|c|c|}
\hline \multirow[b]{2}{*}{ Variables } & \multicolumn{2}{|c|}{ Mean } & \multicolumn{2}{|c|}{ Std. Deviation } & \multicolumn{2}{|c|}{ Std. Error } & \multirow{2}{*}{$\begin{array}{l}\text { Sig. T-test of } \\
\text { equality of means }\end{array}$} & \multicolumn{2}{|c|}{$\mathbf{9 5 \%}$ Confidence Intervals } \\
\hline & High & Low & High & Low & High & Low & & Lower & Upper \\
\hline Overall Awareness & 3.656 & 3.764 & 1.255 & 1.206 & 0.128 & 0.128 & 0.553 & -0.465 & 0.250 \\
\hline Overall Concern & 5.010 & 5.035 & 2.013 & 1.979 & 0.207 & 0.213 & 0.935 & -0.611 & 0.562 \\
\hline Overall Effectiveness & 11.264 & 11.183 & 3.282 & 3.577 & 0.344 & 0.395 & 0.877 & -0.949 & 1.110 \\
\hline Seeking Medical Help & 3.407 & 3.333 & 0.856 & 0.961 & 0.089 & 0.105 & 0.595 & -0.198 & 0.344 \\
\hline $\begin{array}{l}\text { *Awareness of } \\
\text { tick diseases in Missouri }\end{array}$ & 0.864 & 0.944 & 0.244 & 0.232 & 0.035 & 0.025 & 0.066 & -0.165 & 0.006 \\
\hline $\begin{array}{l}\text { Awareness of } \\
\text { tick diseases in region }\end{array}$ & 0.698 & 0.730 & 0.462 & 0.446 & 0.047 & 0.047 & 0.628 & -0.164 & 0.099 \\
\hline Concern for ticks & 2.647 & 2.558 & 1.049 & 1.058 & 0.108 & 0.114 & 0.945 & -0.320 & 0.299 \\
\hline $\begin{array}{l}\text { Concern for contracting } \\
\text { a tick disease }\end{array}$ & 2.463 & 2.506 & 1.089 & 0.995 & 0.112 & 0.108 & 0.785 & -0.351 & 0.265 \\
\hline *Use of prev. methods & 0.625 & 0.700 & 0.487 & 0.461 & 0.052 & 0.051 & 0.308 & -0.219 & 0.069 \\
\hline
\end{tabular}

Note: High and Low columns identify those values for counties of high incidence and low incidence of HME * Indicates assumed unequal variances based on Levine's Test of equality of variances 
This figure is to show the over awareness people tended to have for the less common disease in the region of Lyme, and less awareness of the diseases that do exist in the region, such as HME and tularemia.

When overall awareness scores, measured as the sum of all questions pertaining to tick-disease awareness of all four study counties, were used as the dependent variable in linear multiple regression analysis, the number of years of further education was a significant predictor variables at $\alpha=0.05$ with a $p$-value $<0.005$ (Table 3 ). Overall concern for ticks and tick-borne diseases was also found significant at a p-value $<0.05$. These findings indicate that those who have more education are generally more aware of tick diseases in Missouri, in their respected general region, and overall are more knowledgeable of each of the specific tick-borne diseases asked about on the survey. The magnitude of the education standardized beta also suggests that education is a very important variable in determining the awareness HME and other tick diseases. Finally, these findings also show the important positive relationship between level of awareness of ticks and tick-borne diseases and concern and perceived risk for this disease (Table 3).

When individuals were asked to describe how they were familiar with any of the specific diseases asked about in the survey, those that chose to respond in the open-ended question indicated they heard about these diseases through word of mouth, the news, knowing someone with a specific tick disease, reading about it, having or knowing someone with a medical or veterinary background, working outdoors, or being diagnosed with a tick-borne disease themselves. A surprisingly large amount of people indicated they knew someone that had been diagnosed with a tick-disease, particularly Lyme disease (Figure 7). 
Table 3. Multiple Linear Regression Results for Selected Independent Variables

\begin{tabular}{lccc}
\hline \multicolumn{1}{c}{ Variables } & $\begin{array}{c}\text { Awareness } \\
\text { Beta }\end{array}$ & $\begin{array}{c}\text { Concern } \\
\text { Beta }\end{array}$ & $\begin{array}{c}\text { Effectiveness } \\
\text { Beta }\end{array}$ \\
\hline Classification of Residency & -0.046 & 0.099 & -0.090 \\
Yard Description & 0.126 & $0.176^{*}$ & 0.004 \\
Frequency of Finding Ticks & 0.065 & 0.117 & -0.003 \\
Overall Concern & $0.250^{*}$ & - & $0.296^{* *}$ \\
Overall Awareness & - & $0.198^{*}$ & -0.004 \\
Use of Preventative Methods & 0.132 & 0.120 & 0.083 \\
Overall Effectiveness & -0.004 & $0.241^{* *}$ & - \\
Likelihood of Receiving Medical Help & 0.120 & $0.293^{* *}$ & 0.149 \\
Gender & 0.008 & -0.010 & 0.070 \\
Age & 0.057 & 0.021 & 0.048 \\
Education & $0.253^{* *}$ & -0.062 & 0.142 \\
\hline
\end{tabular}

Note: Beta values are standardized values. ${ }^{*}$ indicates significance at $\mathrm{p}$-value $<0.05$ an ** indicates significance at p-value $<0.005$.

This was an interesting find considering Lyme disease is not very prevalent in this region. Of course, the time of the infection and also the location were not specified, so the reported answers of residents who knew someone with Lyme could have been someone several years ago and in a different state. 


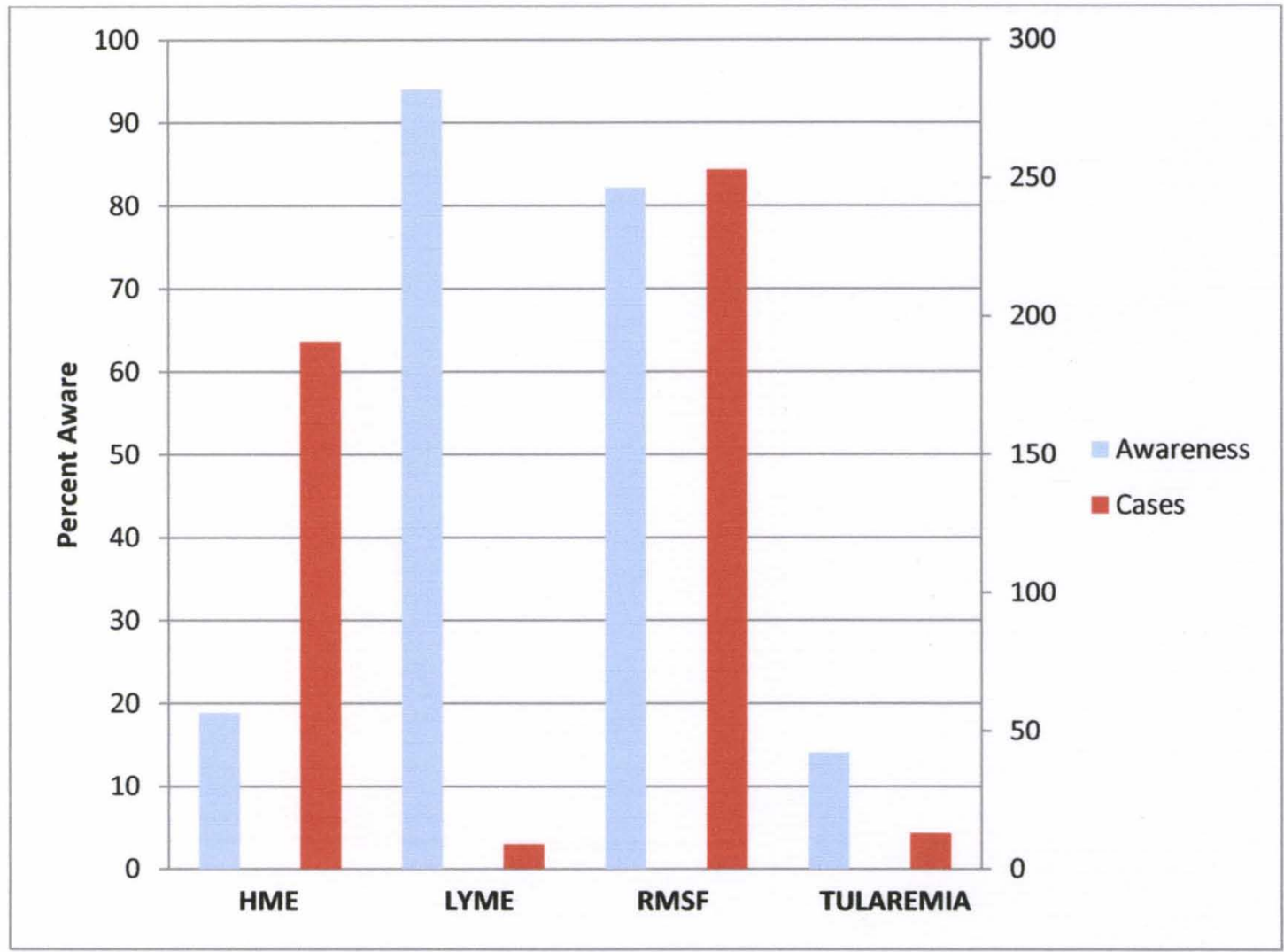

Figure 7. Comparison of awareness of the specific diseases asked about and total number of actual cases of these diseases reported in Missouri in 2009.

\section{Perceived susceptibility and severity}

Part of how an individual perceives whether or not they are susceptible to tickborne diseases was thought to be related to how often they have found ticks on themselves, a family member, or indoor pets such as dogs or cats. When asked how often they find ticks in their place of residence, only $41(22 \%)$ indicated they find ticks very often or frequently, with $120(65 \%)$ indicating they sometimes find ticks and $24(13 \%)$ indicating they never find ticks. 
Individual concern for these diseases is also an indicator of self-perceived susceptibility, as more concerned people may view themselves more susceptible to coming in contact with ticks and contracting a tick-borne disease. When respondents of all four study locations were asked how concerned they were about coming in contact with ticks only $45(24 \%)$ indicated they were very concerned. $51 \%$ indicated they were a little or not at all concerned about coming in contact with ticks. Likewise, when respondents were asked about how concerned they were of contracting a tick-borne disease, $44(24 \%)$ indicated they were very concerned. $106(57 \%)$ were only a little or not at all concerned about contracting a tick-borne disease.

Multiple linear regression analysis with overall concern for ticks and tick-borne diseases revealed that there is a relationship between those who are more concerned about ticks and the diseases they spread and several other factors (see Table 3). Yard description from trimmed and treeless to heavily wooded; overall awareness; the likelihood of receiving medical help if they became symptomatic; and how effective people viewed preventative strategies were positively related to the overall perceived susceptibility and severity regarding concern for ticks and tick diseases, which was in agreement with the finding of concern of Lyme disease with the study by Herrington (2004).

Participating in outdoor activities is an important way a person may come in contact with ticks. Within this study, respondents were also asked to identify briefly any outdoor activities they may participate in. Many of the respondents indicated they would work in the garden or do yard work often during the spring and summer months. Others wrote that they frequently go camping, hiking, hunting, and fishing. 


\section{Efficacy of Preventative Strategies}

Within the Health Belief Model (HBM), part of the reason people may or may not choose to use any preventative measures against infectious diseases may be directly related to how beneficial these preventative strategies are against becoming infected, if they use these methods, and whether or not they would receive medical help should they become symptomatic. With infectious tick diseases, this concept still applies when investigating the use of preventative strategies against ticks and tick bites. The CDC recommends several strategies to prevent or limit contact with ticks and therefore to prevent tick bites that could lead to a tick-borne infection. These strategies are listed on their website (CDC 2011d) and include avoiding wooded/brushy areas all together, wearing light-colored clothing so that spotting ticks is much easier, staying on marked trails when hiking or biking in the woods, and using insect repellent. The HBM assumes that how effective an individual finds these strategies has an impact on whether or not they are used.

Overall, $118(64 \%)$ thought that avoiding wooded/brushy areas was very or somewhat effective in preventing contact with ticks, with $18(10 \%)$ indicating that this strategy was not at all effective. A total of 99 (54\%) respondents indicated that wearing light colored clothing when outdoors was very or somewhat effective, with $32(17 \%)$ noting this method not being effective at all. For the recommended method of staying on marked trails, 97 (53\%) marked this method as very or somewhat effective, but with 34 (18\%) indicating this method was not at all effective. The use of insect repellent seemed to be the most effective preventative strategy in the eyes of residents. $136(73 \%)$ 
residents indicated that the use of insect repellent spray was very or somewhat effective, with only $16(9 \%)$ indicating this method was not very effective.

Multiple linear regressions that analyzed the relationship between the overall effectiveness score derived from how effective residents considered the recommended preventative strategies indicated a significant positive relationship between how an individual perceived the effectiveness of the recommended measures and overall concern (see Table 3). This result suggests that self-perceived susceptibility has a critical implication for how one believes the effectiveness is of these methods and perhaps their usage.

How likely people are to use these preventative methods was also found to be significantly related to overall awareness and concern for ticks and tick-borne diseases, the frequency of finding ticks in place of residence, and age. Based on the discriminant analysis of the use of preventative measures, the more awareness and concern people had for ticks and the diseases they spread seemed to be an important indicator of the likelihood of the use of preventative methods against ticks. In addition, how often ticks were found on themselves, family members, or pets seemed to have an important effect on the decision to use these methods. Older populations, however, were less inclined to use these recommended methods. This is an important finding because the CDC and Missouri Department of Health and Senior Services identify older populations at greater risk of contracting a tick-borne disease. The fact that older populations are less likely to use preventative strategies may be an important reason, as well as reasons related to immune status, why older populations are more prone to these diseases. 
The discriminant analysis results suggest an important relationship between those who use preventative measures and those who do not based on the significant discriminant variables determined from this analysis (Table 4). To test whether or not there is a difference between the two discriminant classes of preventative measures users and nonusers, Wilks' lambda test of the null hypothesis was used. With a Wilks' lambda of 0.819 , this suggests that about $19.1 \%$ of the variability between the two classes can be explained by these discriminant variables. A high value for Wilks' lambda represents a lesser distinction between the two groups of users and non-users; nonetheless this finding has important implications for identifying different behavioral factors that influence the use of preventative measures.

Based on the calculated Wilks' lambda significance at $p<0.0001$, this model rejects the null hypothesis that those who use preventative measures are classified with the same discriminant average as those who do not. This means that overall distinction between groups of users of preventative measures and non-users is significant. Furthermore, the classification summary correctly classified $68.7 \%$ of the original observations based on the significant discriminant variables. Both methods of listwise missing-value treatment and eliminating the income variable from the analysis yielded similar results. The listwise analysis $(\mathrm{N}=126)$ instead of the analysis of the exclusion of the income variable is included as the result for this analysis because the eigenvalue (0.220) that describes the discrimination between the groups of users of preventative measures and non users is higher and has a higher canonical correlation $(0.425)$, which indicates that the observed variability between these groups is explained by the differences (Table 5) (Norušis 2008). 
Several factors may be important in determining whether or not a person uses preventative methods against ticks when outdoors. When reviewing the written responses from residents who responded how they were aware of diseases in Missouri and in the area, an interesting pattern was uncovered. When residents were asked how they were aware of any of the diseases, many (49) indicated they knew or heard of someone who had been diagnosed with a tick-borne disease. Of these who had a personal connection through friends or family with tick diseases, several (16) still indicated they do not use any preventative strategies. This means that $32.6 \%$ of the respondents who knew someone with a tick-borne disease still did not use any preventative measures when outdoors.

Furthermore, of all the people who took the time to share their knowledge of how they were aware of these diseases through the open-ended question, several $(29,27 \%)$ of these respondents still indicated they did not use preventative measures. These findings suggest that there may be ambivalence in the decision making of using preventative strategies to protect one's self from ticks in some of the populations

\section{Directional Cue to Action}

The method of obtaining information about ticks, the diseases they spread, and ways to prevent and limit contact with ticks is an important consideration when trying to understand why there are differences in awareness of these diseases. Information about ticks and tick-borne diseases can be found easily on the Internet, but this method may not be as accessible to some people. 
Table 4. Discriminant Variables of Use of Preventative Measures Model

\begin{tabular}{lccc}
\hline $\begin{array}{c}\text { Variable } \\
\text { In Model }\end{array}$ & $\begin{array}{c}\text { Standardized } \\
\text { Coefficients }\end{array}$ & $\begin{array}{c}\text { Wilks' } \\
\text { lambda }\end{array}$ & $\begin{array}{c}\text { Structure } \\
\text { Matrix }\end{array}$ \\
\hline Frequency of Finding Ticks & 0.427 & 0.847 & 0.530 \\
Overall Concern & 0.544 & 0.862 & 0.590 \\
Overall Awareness & 0.484 & 0.852 & 0.537 \\
Age & -0.538 & 0.862 & -0.358 \\
\hline
\end{tabular}

Table 5. Discriminant Analysis Results of the Preventative Measures Model

\begin{tabular}{ccccc}
\hline Eigenvalue & $\begin{array}{l}\text { Canonical } \\
\text { Correlation }\end{array}$ & $\begin{array}{l}\text { Wilks' } \\
\text { lambda }\end{array}$ & $\begin{array}{c}\text { Chi } \\
\text { Square }\end{array}$ & Significance \\
\hline 0.220 & 0.425 & 0.819 & 24.304 & 0.000 \\
\hline
\end{tabular}

To better understand what educational material is available, and what other methods of distribution of information about these diseases is accessible, respondents were asked to answer this question in the survey.

Most of the respondents who answered this question indicated that pamphlets and flyers at state and national parks on ticks and tick-borne diseases should be more readily available. Likewise, several expressed an interest that there should be seminars provided by the county health department on the importance of tick-borne diseases and methods to use to prevent or limit contact with ticks. Some also thought that local cases of tickborne diseases should be mentioned in the news, especially during peak times of tick 
activity. Others thought that insect repellent could be available at state and national parks and camp grounds more readily, along with information and frequent warnings.

According to the state and county health departments, many of these information sources mentioned by the residents are available. The county health departments do attempt to reach out to the general public about the dangers associated with ticks and tick-borne diseases and utilize a variety of methods to do so. For example, one method is the health departments provide flyers and pamphlets to be distributed to residents in shopping bags of major retail stores such as Wal-Mart during peak tick activity times of spring and summer months. Other methods available include seminars and talks about the importance of preventing ticks and how to remove attached ticks and what symptoms to look for. How accessible these sources are, and how well they are advertised may be important elements to consider when reaching out to the public.

The source of where people would go to find more information about ticks and tick diseases and methods to prevent exposure is also important. The health departments utilize many strategies to attempt to reach out to populations to educate residents about the risks associated with ticks. Overall, $112(61 \%)$ indicated they would first seek information from their physician or health department (Figure 8). In addition, a total of $44(24 \%)$ said they would use the Internet to find out more information, $15(8 \%)$ would get their information from the news on the television, $9(6 \%)$ would talk to a family member or friend, and 3(2\%) would listen to the radio or read the newspaper. 


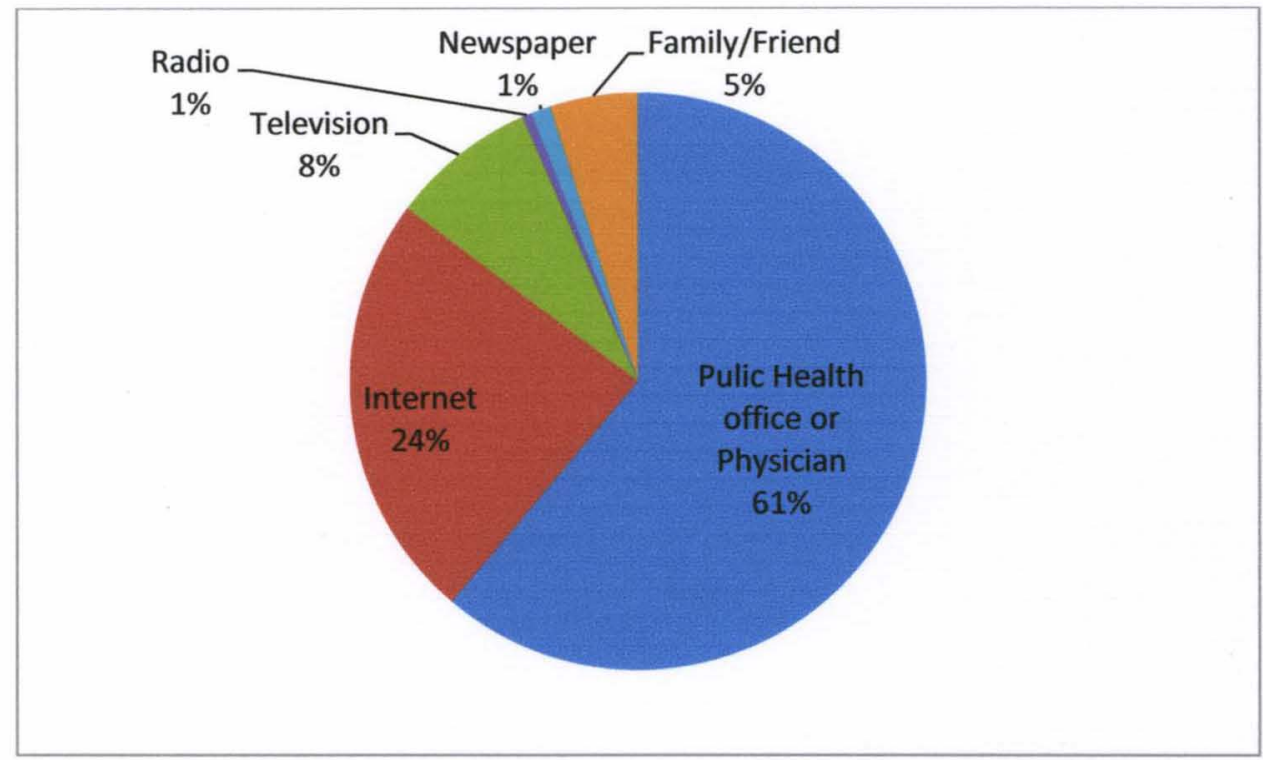

Figure 8. Source of information on ticks and tick-borne diseases 


\section{CHAPTER V}

\section{DISCUSSION}

When it comes to understanding the distribution of ticks and tick-borne diseases, understanding the environmental and ecological factors that play a key role in the sustaining of the population of the ticks is vital. What is also important to understand is how the awareness and perceived risk and seriousness of these diseases in the population residing in these locations and those who frequently participate in outdoor activities have an effect on the spatial distribution of these diseases. Through the theoretical framework of disease ecology and the adoption of the Health Belief Model (HBM), these elements were measured in the residents of selected Missouri counties.

The results of this study suggest that there may be an overall difference in the level of awareness of tick-borne diseases that are present in the state. Fewer residents living in counties with high incidence of Human Monocytic Ehrlichiosis (HME) between 2005 and 2009 were aware that cases of tick-borne diseases occur in Missouri than those living in low incidence regions. The reason that there was not a significant difference in residents' knowledge of tick diseases in their respected region is that there was an overall uniform level of awareness of these diseases occurring close to home.

Not finding any other significance in the overall awareness score that included the summed responses of all questions regarding awareness of tick diseases, overall concern, effectiveness, and the likelihood of seeking medical help may be due to a number of 
factors. One factor could be due to the sample size. A much larger sample size through multiple methods of distribution could yield better, more accurate results. More importantly, the way the questions were worded may have had an effect on choosing an answer. For instance, providing choices for the different types of tick-borne diseases instead of asking residents to list the diseases they are familiar with may have overestimated overall awareness of these diseases.

Where residents go if they do become symptomatic may also have had a misleading effect on where these diseases occur. Ralls County, for example, is mostly rural; the nearest hospital for most of the residents in the county is in the northernneighboring county. This county is classified as having a high average incidence of reported HME cases, and many of these cases may be from residents of neighboring counties. While most people may go to their family physician if symptoms develop, these reported cases may become somewhat misrepresented. To understand the overall reporting of cases for future research will need to involve the movement of people across political boundaries. This study also does not consider the possibility of residents of other regions travelling to other parts of the state for outdoor leisure activities and becoming infected there, only to become symptomatic once they return to their home county. Overall, however, there does seem to be an important difference in overall awareness between high incidence counties and low incidence counties, indicating that knowledge of ticks and tick-borne diseases has an important impact on the distribution of reported cases.

To further understand the portion of the population who are more aware of these diseases, multiple linear regression analysis was used. The finding in this analysis 
indicates that education has a positive relationship with knowledge and awareness of tick diseases, and brings to attention the populations that are less aware. People with less education may not have had the exposure to the information about the risks associated with ticks. These results have important implications for health departments the need to focus attention of awareness on the portion of the population that has less education.

The awareness of the general tick diseases that are prevalent in Missouri was also striking. Most people indicated they were aware of Lyme disease. This is an interesting finding because Lyme disease is not common in this part of the country. Most Lyme cases are in the New England areas as well as Wisconsin and Northern Illinois, with very few occurring in Missouri. The fact that most of the population was aware of Lyme disease and not as aware of diseases such as HME, which is prevalent in Missouri, may signify an important difference in presenting information of national cases of diseases such as Lyme disease compared to a more local area of Missouri. While overall high knowledge of any tick-borne disease may be important in leading to the use of preventative measures against all tick diseases, it still may have in general negative consequences of causing residents to not realize that the Lyme cases they are hearing elsewhere may not occur close to home, but other types of tick diseases do.

The perceived susceptibility and how concerned people are about coming in contact with ticks and contracting a tick-borne disease was positively related to the yard description. Yard description ranged from trimmed and treeless to heavily wooded. These findings suggest a positive relationship between concern and living in dense wooded rural areas. Concern was also positively related to awareness, which highlights the important relationship between being concerned for tick diseases and knowledge and 
awareness of them. More concern also suggests a higher likelihood of receiving medical help if they became symptomatic after finding a tick attached. This could be due to the already elevated perceived risk and seriousness one has of the disease included in the overall concern. People of higher concern and self-perceived risk also elevated the effectiveness they believed in the preventative methods recommended by the CDC. This suggests that people with a higher sense of perceived risk and seriousness of HME are aware of the importance of and perhaps know how to properly use and get the most effectiveness out of the preventative methods.

Overall, most of the population determined that the use of insect repellent and simply avoiding brushy/wooded areas are the most effective way to minimize contact with ticks and limit the chances of becoming infected with a tick-borne disease. The use of repellent is a cheap way to minimize exposure to ticks, and limit the number of tick bites one receives. A further analysis of why more people do not utilize this method would provide important information regarding to certain reasons people choose not to protect themselves when they are outdoors.

The efficacy of these methods was found to be directly related to how concerned people were about ticks and diseases such as HME. Greater concern about these diseases seems to lead to using preventative methods. Being cognizant about self-perceived risk may have a positive effect on the decision to use preventative methods.

Overall awareness, concern, frequency of finding ticks, and age were important discriminating variables classifying preventative measures users and non users. Knowledge of these diseases and perceived risk of coming in contact with ticks seem to play an important role in the decision-making of whether to use preventative measures or 
not. The more aware someone is of these risks may be an important factor that is tied in with self-perceived risk and the decision to protect one's self. Age may be an important factor because older populations may be targeted more by health departments because of declining immune status and chances of becoming symptomatic if they do become infected.

The fact that several respondents of the study who indicated they knew someone who had been diagnosed with a tick disease still did not use preventative measures themselves suggest an ambivalence in the population. Knowing the debilitating effect these diseases can have on a person, one would assume that a larger portion of this population would use preventative measures. There seems to be some disconnect between the diseases and the methods by which one becomes ill. Perhaps this is due to the long incubation period between being bitten by a tick and the time of onset of symptoms. Regardless, this presents important challenges to consider when determining how knowledge and preventative practices are related to one another.

Ambivalence has been shown to be an important factor in health decision making for populations that are aware of the risks associated with a certain behavior, yet continue to engage in that behavior. Studies on healthy food choice (Sparks et al. 2001), and pregnancy and contraception use among teens (Bruckner et al. 2004) suggest that ambivalence is a significant issue when it comes to the decision of using preventative methods against ticks and has important implications to understanding why people who have direct knowledge of the consequences of these diseases still do not use methods to keep themselves safe. 


\section{Limitations of the Study}

This study was a way to enhance the existing GIS literature on the spatial distribution of ticks and HME in a unique way that incorporated awareness and perceived risk and seriousness of people living in Missouri. Only a few GIS studies (mentioned in Chapter 2) have been done in this region, meaning other methods of GIS analysis could lead to other results that provide a better endemic risk map that represents the reported cases more accurately.

The use of short surveys can be an effective way to get a lot of data from the population but in regards to the depth and type of information drawn from these surveys can be limited. This study attempted to limit the amount of time necessary for respondents to participate in filling out the survey, but in doing so limited the amount and type of information that could have been included. Further in-depth surveys that required more time could provide a more detailed set of information pertaining to travelling to state and national parks, the types of preventative measures that are used, and reasons for not using them.

This method of survey distribution may have created recall and reporting biases. Specifically, the structure of the survey asked respondents to select from the disease names they were familiar with. This may have lead to a higher reporting bias that included people indicating they were aware of these diseases when in fact they may not have been. Respondents may have also been hesitant to accurately record whether or not they used recommended preventative methods. Furthermore, many participants were not comfortable revealing their personal information, including income and education. 
Only people who happened to visit the post office during the time the research surveys were being distributed had the opportunity to participate. This method of distribution provided a convenient way to come in contact with residents of each study county. The inclusion of different ethnicities in this analysis was also limiting since most of the respondents were white. A combination of distribution methods could have produced a larger sample size as well.

\section{Future Research}

Further research in understanding the distribution of diseases and why diseases occur where they do is vital to creating treatment plans and preventative strategies and education aimed at the public. Expanding the use of other or multiple methods in measuring the spatial patterns is imperative to this understanding. Follow up analysis of the population included in the region of GIS modeling is one way that may elucidate the results more and provide meaningful explanations to the disparate results and inconsistencies within the model itself. This application can be used toward other tickborne diseases such as Lyme disease, but is not limited to just these types. Studies aimed in understanding spatial patterns of urban mosquitoes and diseases they spread can be further enhanced by the use of methods that include information from the population within urban and suburban neighborhoods.

Further incorporation of perceived risk and awareness needs to be included to further understand spatial patterns of diseases because doing so acknowledges the variability and uncertainty of human behavior and awareness that other spatial models simply do not. Understanding the human aspect of human diseases is critical in further 
enhancing our understanding of the geography of diseases and the combination of environmental and social factors that are closely intertwined.

Other future work may be done on the positive and negative effects of controlled burns in regions where people are likely to come in contact with ticks, such as state parks and camp grounds, or on private wooded properties. While it may not be possible to cover large regions with controlled burns, this may be a beneficial way to limit the density of local tick populations by eliminating key habitat cover provided by the fallen leaves during the winter months. Future research could investigate the impact this method has and the perceived risk and dangers associated with such methods. 


\section{CHAPTER VI}

\section{CONCLUSION}

This study was a way to enhance GIS studies to further understand the distribution of Human Monocytic Ehrlichiosis (HME) as well as other tick-borne diseases. The inclusion of awareness and perceived risk and threats of HME and other tick-borne diseases with spatial analysis allowed for a deeper understanding of the distribution of this disease. An important reason for the observed disparities between predicted risk mapping and actual reported HME cases was suggestively found to be the differences in overall awareness of tick-borne diseases by residents.

Little or no prior research has been done to investigate the relationship between people and their environment that considers the disparate perceived risks and awareness of HME. Furthermore, while some research investigates similar questions using surveys on an individual level, written feedback from the residents themselves that further explains their answers for the survey are not included. This research project included methods that allowed respondents to answer questions through a series of open-ended questions as well as closed-ended questions, which elucidated some of the findings while unveiling important information regarding awareness and the decision factors involved in the use of preventative strategies. In addition, little or no research in vector-borne diseases has used the approach of surveys or questionnaires to link GIS analyses and 
modeling to awareness and susceptibility in an effort to further understand the spatial patterns modeled and observed for these diseases and the disparities between the two.

The methods of this study allowed for a deeper understanding of the relationship of people and their surrounding environment that has been previously overlooked in disease distribution studies. The resulting finding that awareness is a suggestive element in the disparate observed incidences of HME proves to be an important consideration when assessing at-risk populations. Furthermore, the integration of the stratified awareness related to education and income suggest a differing overall awareness of these diseases at a socioeconomic level that has not been considered. The relationship among perceived susceptibility and effectiveness of the recommended preventative strategies also suggest that prior frequent contact with ticks is related to how one determines their risk and the use of these preventative strategies. These relationships have been overlooked by previous studies that were focused solely on determining high-risk zones of HME and other vector-borne diseases. This study was a way to further investigate these relationships.

These results have important implications for identifying populations that may not be aware of important dangerous tick-borne diseases, or do not have access to the free information provided by the county and state health departments. Identifying populations with limited knowledge of the dangers associated with ticks can help focus attention and efforts in providing these resources to those populations. Determining an overall difference in awareness of high/low incidence of HME suggest that knowledge about these diseases is a critical factor in the spatial distribution of the disease. Identifying these key differences allows for state and local health departments to focus resources to 
ensuring that a greater portion of populations are exposed to the education about the risks of these diseases.

Furthermore, following up with GIS modeling studies helps explain the model disparities and allows for considering other approaches to create high-risk mapping that includes possible demographic information as well as environmental data. Research on spatial distributions of zoonotic diseases such as HME and others that rely on the transmission of the pathogen by a vector and ecological and environmental factors have been limited to GIS and other spatial analysis. These studies are vital in understanding the relationships that exist in the natural environment between arthropod vectors and preferred habitats, but do not consider the human variable and the entanglement of the natural and built environments.

Until recently, the geography of health research was dominated by the strict use of mapping and modeling risk areas. New trends of thought have sparked the inclusion of multiple and mixed methods that are focused on further understanding the observed health disparities and attempting to explain why these disparities are occurring where they do. This study provides a useful template to include in spatial and other quantitative research that is pertinent in fully understanding spatial patterns of diseases and at-risk populations. Its applications, to health and non-health research alike, can be employed to bridge the gaps of existing literature and unveil important relationships that may go unnoticed. 


\section{REFERENCES}

Addington-Hall, J., L. Walker, C. Jones, S. Karlsen, M. McCarthy. 1998. A randomized controlled trial of postal versus interviewer administration of a questionnaire measuring satisfaction with, and use of, services received in the year before death. Journal of Epidemiology and Community Health, 52: 802-807.

Barry, John. 2005. The Great Influenza. Penguin Group Publisher, United States.

Bowling, Ann. 2005. Mode of questionnaire administration can have serious effects on data quality. Journal of Public Health, 27(3): 281-291.

Bruckner, Hannah, A. Martin, P.S. Bearman. 2004. Ambivalence and pregnancy: Adolescents' attitude, contraceptive use and pregnancy. Perspectives on Sexual and Reproductive Health, 36(6): 248-257.

Butterworth, M., K. Kolivras, L. Grossman, and K. Redican. 2010. Knowledge, perceptions, and practices: mosquito-borne disease transmission in Southwest Virginia, USA. Southeastern Geographer, 50(3): 366-385.

CDC (Centers for Disease Control and Prevention). 2011a. Ehrlichiosis. Available at http://www.cdc.gov/ehrlichiosis/ (last accessed 4 February 2012)

CDC (Centers for Disease Control and Prevention). 2011b. Tularemia. Available at http://www.cdc.gov/tularemia/ (last accessed 4 February 2012)

CDC (Centers for Disease Control and Prevention). 2011c. Summary of Notifiable Diseases - United States, 2009. Morbidity and Mortality Weekly Report, 58(53).

CDC (Centers for Disease Control and Prevention). 2011d. Preventing Tick Bites. Available at http://www.cdc.gov/ticks/avoid/on_people.html (last accessed 13 April 2012).

CDC (Centers for Disease Control and Prevention). 2010. Summary of Notifiable Diseases - United States, 2008. Morbidity and Mortality Weekly Report, 57(54).

CDC (Centers for Disease Control and Prevention). 2009. Summary of Notifiable Diseases - United States, 2007. Morbidity and Mortality Weekly Report, 56(53). 
CDC (Centers for Disease Control and Prevention). 2008. Summary of Notifiable Diseases - United States, 2006. Morbidity and Mortality Weekly Report, 55(53).

CDC (Centers for Disease Control and Prevention). 2007. Summary of Notifiable Diseases - United States, 2005. Morbidity and Mortality Weekly Report, 54(53).

Center for Biosecurity of UPMC. Tularemia Fact Sheet. Available at http://www.upmcbiosecurity.org/website/our_work/biological-threats-andepidemics/fact_sheets/tularemia.html (last accessed 10 April 2012)

Cheek, Julianne. 2004. At the margins? Discourse analysis and qualitative research. Qualitative Health Research, 14(8): 1140-1150.

Dyck, Isabel. 1999. Using qualitative methods in medical geography: deconstructive moments in a subdiscipline? Professional Geographer, 51(2) 243-253.

Garrett, Laurie. 1995. The Coming Plague. Penguin Group Publisher, United States

Gesler, Wilbert M., S.T. Bird, S.A Oljeski. 2009. Disease ecology and a reformist alternative: The case of infant mortality. Social Science \& Medicine, 44(5): 657 671 .

Glanz, K., B.K. Rimer. 1997. Theory at a glance. National Cancer Institute, USA.

Gould, Hannah, R.S. Nelson, K.S. Griffith, E.B. Hayes, J. Piesman, P.S Mead, M.L. Cartter. 2008. Knowledge, attitudes and behaviors regarding Lyme disease prevention among Connecticut residents, 1999-2004. Vector-borne and Zoonotic Diseases, 8(6): 769-776.

Gratz, Norman G. 1999. Emerging and resurging vector-borne diseases. Annual Review of Entomology, 44: 51-75.

Gregory, Derek, R. Johnston, G. Pratt, M.J. Watts, S. Whatmore (eds). 2009. The Dictionary of Human Geography $5^{\text {th }}$ ed. Blackwell Publishing, United Kingdom.

Gubler, Duane J. 1998. Resurgent vector-borne diseases as a global health problem. Emerging Infectious Diseases, 4(3): 442-450.

Guerra, M., E. Walker, C. Jones, S. Paskewitz, M. R. Cortinas, A. Stancil, L. Beck, M. Bobo, U. Kitron. 2002. Predicting the risk of Lyme disease: habitat suitability for Ixodes scapularis in the North Central United States. Emerging Infectious Diseases, 8(3): 289-298.

Guo, Xulin, K.P. Price, and J. Stiles. Grassland discriminant analysis using landsat TM signle and multitemporal data. Photogrammetric Engineering \& Remote Sensing, 69 (11): 1255-1262. 
Herrington, James. 2004. Risk perceptions regarding ticks and Lyme disease: a national survey. American Journal of Preventive Medicine, 26(2): 135-140.

Herrington, J.E., G.L. Campbell, R.E. Bailey, M.L. Cartter, M.Adams, E.L. Frazier, T.A. Damrow, K.F. Gensheimer. 1997. Predisposing factors for individuals' Lyme disease prevention practices: Connecticut, Maine, and Montana. American Journal of Public Health, 87(12): 2035-2038.

Holt, Amanda. 2010. Using the telephone for narrative interviewing: a research note. Qualitative Research, 10(1): 113-121.

Kearns, Robin, G. Moon. 2002. From medical to health geography: novelty, place and theory after a decade of change. Progress in Human Geography, 26(5): 605-625.

Keefe, L.M., M.H. Moro, J. Vinasco, C. Hill, C. C.Wu, E.A. Raizman. The use of harvested white-tailed deer (Odocoileus virginianus) and Geographic Information System (GIS) methods to characterize distribution and locate spatial clusters of Borrelia burgdorferi and its vector Ixodes scapularis in Indiana. Vector-borne and Zoonotic Diseases, 9(6): 671-680.

King, Bryan. 2010. Political ecologies of health. Progress in Human Geography, 34(1): $38-55$.

Krysan, M., H. Schuman, L.J. Scott, P. Beatty. 1994. Response rates and response content in mail versus face-to-face surveys. Public Opinion Quarterly, 58(3): 381-399.

Leeuw, De, Edith D., G.J. Mellenbergh, J.J. Hox. 1996. The influence of data collection methods on structural models: a comparison of mail, a telephone, and a face-toface survey. Sociological Methods and Research, 24(4): 443-472.

Litva, Andrea, J. Eyles. 1995. Coming out: exposing social theory in medical geography. Health and Place, 1(1): 5-14.

Lobo, Agustin. 1997. Image segmentation and discriminant analysis for identification of land cover units in ecology. Transactions on Geoscience and Remote Sensing, 35(5): 1136-1145.

Lockhart, J.M., Davidson, W.R., Stallknecht, D.E., Dawson, J.E., Howerth, E.W. 1997. Isolation of Eherlicha chaffeensis from wild white-tailed deer (Odocoileus virginianus) confirms their role as natural reservoir hosts. Journal of Clinical Microbiology 35(7): 1681-1686.

Mahy, B.W.J. 2004. Vector-borne diseases. Microbe-vector interactions in vector-borne diseases. eds. S.H. Gillespie, G.L. Smith, A. Osbourn. Cambridge, UK. 
Mayer, Jonathan D. 1992. Challenges to understanding spatial patterns of disease: philosophical alternatives to logical positivism. Social Science and Medicine, 35(4): 579-587.

Mayer, Jonathan D. 1994. A reformed medical geography reconsidered. Professional Geographer, 46(1): 103-106.

Mayer, Jonathan D. 1996. The political ecology of disease as one new focus for medical geography. Progress in Human Geography, 20(4): 441-456.

Mellor, P.S. 2004. Environmental influences on arbovirus infections and vectors. Microbe-vector interactions in vector-borne diseases. eds. S.H. Gillespie, G.L. Smith, A. Osbourn. Cambridge, UK.

Niedomysl, Thomas, and B. Malmberg. 2009. Do open-ended survey questions on migration create coder variability problems? Population, Space and Place, 15(1): 79-87.

Norušis, Marija J. 2008. SPSS 16.0 Statistical Procedure Companion. Prentice Hall Inc., New Jersey, United States.

Ozdenerol, Esra, E. Bialkowska-Jelinska, and G.N. Taff. 2008. Locating suitable habitats for West Nile Virus-infected mosquitoes through association of environmental characteristics with infected mosquito locations: a case study in Shelby County, Tennessee. International Journal of Health Geographics, 7(12).

Paddock, C.D., Childs, J.E. 2003. Ehrlichia chaffeensis: a prototypical emerging pathogen. Clinical Microbiology Reviews 16(1): 37-64.

Philip, L.J. 1998. Combining quantitative and qualitative approaches to social research in human geography - an impossible mixture? Environment and Planning, 30: 261-276.

Parker, C., M. Dewey. 2000. Assessing research outcomes by postal questionnaire with telephone follow-up. International Journal of Epidemiology, 29(6): 1065-1069.

Parveen, Salina, K.M. Portier, K. Robinson, L. Edmistion, and M.J. Tamplin. 1999. Discriminant analysis of ribotype profiles of Escherichia coli for differentiating human and nonhuman sources of fecal pollution. Applied and Environmental Microbiology, 65(7): 3142-3147.

Randolph, S. E. 2004. Evolution of tick-borne disease systems. Microbe-vector interactions in vector-borne diseases. eds. S.H. Gillespie, G.L. Smith, A. Osbourn. Cambridge, UK. 
Sibbald,B., J Addington-Hall, D Brenneman, and P Freeling. 1994. Telephone versus postal surveys of general practitioners: methodological considerations. The British Journal of General Practice, 44(384): 297-300.

Smyth, Fiona. 2008. Medical geography: understanding health inequalities. Progress in Human Geography, 32(1): 119-127.

Sparks, Paul, M. Conner, R. James, R. Shepherd, R. Povey. 2001. Ambivalence about health-related behaviours: An exploration in the domain of food choice. British Journal of Health Psychology, 6(1): 53-68.

Starks, Helene, S.B. Trinidad. 2007. Choose your method: A comparison of phenomenology, discourse analysis, and grounded theory. Qualitative Health Research, 17(10): 1372-1380.

Stein, K.J., Waterman, M., Waldon, J.L. 2008. The effects of vegetation density and habitat disturbance on the spatial distribution of ixodid ticks (Acari: Ixodidae). Geospatial Health 2(2): 241-252.

STOP (Stop Ticks on People) 2009. Ticks and diseases. Accessed on Dec 3, 2011 from http://www.stopticks.org/ticks/index.asp

Wimberly, M.C., Yabsley, M.J., Baer, A.D., Dugan, V.G., Davidson, W.R. 2008a. Spatial heterogeneity of climate and land-cover constraints on distributions of tick-borne pathogens. Global Ecology and Biogeography 17: 189-202.

Wimberly, M.C., A.D. Baer, and M.J. Yabsley. 2008b. Enhanced spatial models for predicting the geographic distributions of tick-borne pathogens. International Journal of Health Geographics, 7(15).

Yabsley, M.J., Wimberly, M.C., Stallknect, D.E., Little, S.E., Davidson, W.R. 2005. Spatial analysis of the distribution of Ehrlichia chaffeensis causative agent of human monocytotropic ehrlichiosis, across a multi-state region. American Journal of Tropical Medicine and Hygiene 76(6): 840-850.

WHO (World Health Organization). 2011. Vector-borne disease. Accessed 2011, available at http://www.who.int/heli/risks/vectors/vector/en/

Zimmerer, Karl S. 2007. Cultural ecology (and political ecology) in the 'environmental borderlands': exploring the expanded connectivities within geography. Progress in Human Geography, 31(2): 227-244.

Zeilhofer, Peter, E.S. dos Santos, A.L.M. Ribeiro, R.D. Miyazaki, M.A. dos Santos. 2007. Habitat suitability mapping of Anopheles darling in the surroundings of the Manso hydropower plant reservoir, Mato Grosso, Central Brazil. International Journal of Health Geographics, 6(7). 


\section{University of Louisville}

\section{Department of Geography and Geosciences}

The purpose of this survey is to determine knowledge, perception and practices toward tick borne diseases on a local community level. The information provided will remain confidential and no personal identifying information is requested. All questions are optional, and you may choose not to answer any of the following. Your participation in this study is much appreciated. Thank you! RESIDENTIAL INFORMATION

1. How long have you been a resident of this county?

2. How would you classify your place of residence?

$\square$ Urban $\quad \square$ Suburban $\square$ Rural $\square$ Other

3. How would you describe where you live?

$\square$ House/rental house $\square$ Apartment Complex/Condo $\square$ Mobile Home Other

4. How would you describe your yard?

$\square$ None $\square$ Trimmed/Treeless $\quad \square$ Few Trees/Shrubs $\square$ Bordering wooded lands $\square$ Heavily Wooded $\square$ Other

\section{AWARENESS/SUSCEPTIBILITY}

5. Are you aware of any diseases spread by ticks in Missouri? $\quad \square$ Yes $\square$ No

6. Are you aware of any diseases spread by ticks in your area? $\quad \square$ Yes $\quad \square$ No

7. Have you heard of any of the following tick borne diseases?

$\begin{array}{lll}\text {-Ehrlichiosis } & \square \text { Yes } & \square \text { No } \\ \text {-Lyme Disease } & \square \text { Yes } & \square \text { No } \\ \text {-Rocky Mountain Spotted Fever } & \square \text { Yes } & \square \text { No } \\ \text {-Tularemia } & \square \text { Yes } & \square \text { No }\end{array}$

8. Please describe how you are familiar with the disease(s) if you selected 'yes' for any of the above.

9. How often do you find ticks on yourself, family members, or pets, of your residence?

$\square$ Very Often $\square$ Frequently $\square$ Sometimes $\square$ Never

10. Where would you first seek information on tick-borne diseases in your area?
$\square$ Television
$\square$ Newspaper
$\square$ Radio
Internet
$\square$ Physician
Public Health Office
$\square$ Family/Friend 
Appendix A

11. Please describe any outdoor activities you and/or your family take part in (work or leisure).

12. Please describe what type of education practices are/should be available to prevent tickborne diseases

13. How concerned are you about coming in contact with ticks in your area?

$\square$ Very $\square$ Somewhat $\square$ A little $\square$ Not at all

14. How concerned are you about contracting a tick borne disease?

$\square$ Very $\square$ Somewhat $\square$ A little $\square$ Not at all

15. Do you use any preventative methods against ticks? $\square$ Yes $\square$ No

16. Please select how effective you find the following tick preventative measures:

\begin{tabular}{|c|c|c|c|c|}
\hline -Avoid wooded/brushy areas & $\square$ Very & $\square$ Somewhat & $\square$ A little & $t$ all \\
\hline -Wearing light-colored clothing & Jvery & Somewhat & little & all \\
\hline -Staying on marked trails & ПVory & Somewhat & little & \\
\hline Using insect repellent & & $\square$ Somewhat & A little & \\
\hline
\end{tabular}

17. If you became ill after finding a tick attached, how likely do you feel that you would seek medical help?

$\square$ Very $\quad \square$ Somewhat $\quad \square$ A little $\square$ Not at all

\section{DEMOGRAPHIC INFORMATION (all information will remain confidential)}

18. Please select your gender

$$
\square \text { Male } \square \text { Female }
$$

19. Which age group best describes you?
$\square 18-24$
$\square 25-34 \quad \square 35-44$
$\square$ 45-54
$\square 55-64$
$65+$

20. Please select your ethnicity

$\square$ African American/Black $\square$ Hispanic $\square$ Caucasian $\square$ Asian Other

21. Please select which level of annual combined income applies to your residence.
$\square$ Less than $\$ 15,000$
$\$ 15,000-24,000$
$\square \$ 25,000-34,000$
$\square 35,000-44,000$
$\square \$ 45,000-54,000$
$\$ 55,000-64,000$
$\square \$ 65,000-74,000$
$\$ 75,000+$

22. Please select the highest education you or a member of your residence has achieved.
$\square$ High School
$\square 2$ Years of College
4 Years of College
$6+$ Years of College

OTHER COMMENTS: 
Appendix B

\section{Overall Awareness and Perceived Risk}

\section{Overall Awareness}

Are you aware of any diseases spread by ticks in Missouri? Are you aware of any diseases spread by ticks in your area? Have you heard of?

\section{Ehrlichiosis:}

Lyme disease:

Rocky Mountain spotted fever:

Tularemia:
Yes: $167(90 \%) \quad$ No: $18(10 \%)$

Yes: $132(71 \%)$ No: $53(29 \%)$

Yes: $35(19 \%) \quad$ No: $150(81 \%)$

Yes: $134(72 \%)$ No: $51(28 \%)$

Yes: $152(82 \%)$ No: $33(18 \%)$

Yes: $26(14 \%)$ No: $159(86 \%)$

How often are ticks found on yourself, family members or pets?

Very often: $15(8 \%) \quad$ Frequently: $26(14 \%) \quad$ Sometimes: $120(65 \%)$ Never: $24(13 \%)$

\section{Perceived Risk/Seriousness}

How concerned are you about coming in contact with ticks?

Very: $45(24 \%) \quad$ Somewhat: $42(23 \%) \quad$ A little: $62(34 \%) \quad$ Not at all: $32(17 \%)$

How concerned are you about contracting a tick-borne disease?

Very: $44(24 \%) \quad$ Somewhat: $30(16 \%) \quad$ A little: $75(41 \%) \quad$ Not at all: $31(17 \%)$

Perceived Benefits/Barriers

Do you use any preventative methods against ticks? $\quad$ Yes: $111(60 \%) \quad$ No: $56(30 \%)$

How effective do you find the following preventative methods?

Avoiding wooded/brushy areas

Very: $69(37 \%) \quad$ Somewhat: $49(26 \%) \quad$ A little: $32(17 \%) \quad$ Not at all: $18(10 \%)$

Wearing light-colored clothing

Very: $44(24 \%) \quad$ Somewhat: $55(30 \%) \quad$ A little: $38(21 \%) \quad$ Not at all: $32(17 \%)$

Staying on marked trails

Very: $46(25 \%) \quad$ Somewhat: $51(28 \%) \quad$ A little: $34(18 \%) \quad$ Not at all: $34(18 \%)$

Using insect repellent

Very: $87(47 \%) \quad$ Somewhat: $49(26 \%) \quad$ A little: $18(10 \%) \quad$ Not at all: $16(9 \%)$

\section{Cue to Action/Self efficacy}

Where would you first seek information on ticks and tick-borne diseases in your area?

Physician/Public Health Office: 112 (61\%) Internet: 44 (23\%) Television: $15(8 \%)$

Radio: $1(1 \%)$

Newspaper: $2(1$

Family/Friend: $9(5 \%)$

If you became ill after finding a tick, how likely would you be to seek medical help?
Very: $108(24 \%)$
Somewhat: $32(17 \%)$
A little: $27(15 \%)$
Not at all: $8(4 \%)$ 
Overall Awareness and Perceived Risk for Counties with High Reported Incidence of HME (Macon and Carter Counties)

\section{Overall Awareness}

Are you aware of any diseases spread by ticks in Missouri? Are you aware of any diseases spread by ticks in your area? Have you heard of?

Ehrlichiosis:

Lyme disease:

Rocky Mountain spotted fever:

Tularemia:

$\begin{array}{ll}\text { Yes: } 83(86 \%) & \text { No: } 13(14 \%) \\ \text { Yes: } 67(70 \%) & \text { No: } 29(30 \%) \\ & \\ \text { Yes: } 17(18 \%) & \text { No: } 79(82 \%) \\ \text { Yes: } 91(95 \%) & \text { No: } 5(5 \%) \\ \text { Yes: } 78(81 \%) & \text { No: } 18(19 \%) \\ \text { Yes: } 15(16 \%) & \text { No: } 81(84 \%)\end{array}$

How often are ticks found on yourself, family members or pets?

Very often: $11(11 \%) \quad$ Frequently: $11(11 \%) \quad$ Sometimes: $60(62 \%) \quad$ Never: $14(15 \%)$

\section{Perceived Risk/Seriousness}

How concerned are you about coming in contact with ticks?

Very: $24(25 \%) \quad$ Somewhat: $20(21 \%) \quad$ A little: $35(36 \%) \quad$ Not at all: $16(17 \%)$

How concerned are you about contracting a tick-borne disease?

Very: $24(25 \%) \quad$ Somewhat: $16(17 \%) \quad$ A little: $35(36 \%) \quad$ Not at all: $20(21 \%)$

\section{Perceived Benefits/Barriers}

Do you use any preventative methods against ticks? $\quad$ Yes: 55 (57\%) No: 33 (34\%)

How effective do you find the following preventative methods?

Avoiding wooded/brushy areas

Very: $36(38 \%) \quad$ Somewhat: $30(31 \%) \quad$ A little: $14(15 \%) \quad$ Not at all: $8(8 \%)$

Wearing light-colored clothing

Very: $23(24 \%) \quad$ Somewhat: $31(32 \%) \quad$ A little: $19(20 \%) \quad$ Not at all: $17(18 \%)$

Staying on marked trails

Very: $23(24 \%) \quad$ Somewhat: $29(30 \%) \quad$ A little: $16(17 \%) \quad$ Not at all: $18(19 \%)$

Using insect repellent

Very: $41(43 \%) \quad$ Somewhat: $33(34 \%) \quad$ A little: $8(8 \%) \quad$ Not at all: $7(7 \%)$

\section{Cue to Action/Self efficacy}

Where would you first seek information on ticks and tick-borne diseases in your area?

Physician/Public Health Office: 59 (61\%)

Radio: $0(0 \%)$

Internet: $19(20 \%) \quad$ Television: $9(9 \%)$

Newspaper: $1(1 \%) \quad$ Family/Friend: $6(6 \%)$

If you became ill after finding a tick, how likely would you be to seek medical help?

Very: $57(59 \%) \quad$ Somewhat: $16(17 \%) \quad$ A little: $16(17 \%) \quad$ Not at all: $2(2 \%)$

Appendix B 
Overall Awareness and Perceived Risk for Counties with Low Incidence of HME (Douglas and Ralls Counties)

\section{Overall Awareness}

Are you aware of any diseases spread by ticks in Missouri? Are you aware of any diseases spread by ticks in your area? Have you heard of?

Ehrlichiosis:

Lyme disease:

Rocky Mountain spotted fever:

Tularemia:

$\begin{array}{ll}\text { Yes: } 84(94 \%) & \text { No: } 5(6 \%) \\ \text { Yes: } 65(73 \%) & \text { No: } 24(27 \%) \\ & \\ \text { Yes: } 18(20 \%) & \text { No: } 71(80 \%) \\ \text { Yes: } 83(93 \%) & \text { No: } 6(7 \%) \\ \text { Yes: } 74(83 \%) & \text { No: } 15(17 \%) \\ \text { Yes: } 11(12 \%) & \text { No: } 78(88 \%)\end{array}$

Yes: $84(94 \%) \quad$ No: $5(6 \%)$

How often are ticks found on yourself, family members or pets?
Very often: 4 (4\%)
Frequently: $15(17 \%)$
Sometimes: $60(67 \%)$
Never: $10(11 \%)$

\section{Perceived Risk/Seriousness}

How concerned are you about coming in contact with ticks?

Very: $21(24 \%) \quad$ Somewhat: $22(25 \%) \quad$ A little: $27(30 \%) \quad$ Not at all: $16(18 \%)$

How concerned are you about contracting a tick-borne disease?
Very: $20(22 \%)$
Somewhat: $14(16 \%)$
A little: $40(45 \%)$
Not at all: $11(12 \%)$

\section{Perceived Benefits/Barriers}

Do you use any preventative methods against ticks?

How effective do you find the following preventative methods?

Avoiding wooded/brushy areas

Very: $33(37 \%) \quad$ Somewhat: $19(21 \%) \quad$ A little: $18(20 \%) \quad$ Not at all: $10(11 \%)$

Wearing light-colored clothing

Very: $21(24 \%) \quad$ Somewhat: $24(27 \%) \quad$ A little: $19(21 \%) \quad$ Not at all: $15(17 \%)$

Staying on marked trails

Very: $23(26 \%) \quad$ Somewhat: $22(25 \%) \quad$ A little: $18(20 \%) \quad$ Not at all: $16(18 \%)$

Using insect repellent

Very: $46(52 \%) \quad$ Somewhat: $16(18 \%) \quad$ A little: $10(11 \%) \quad$ Not at all: $9(10 \%)$

\section{Cue to Action/Self efficacy}

Where would you first seek information on ticks and tick-borne diseases in your area?

Physician/Public Health Office: $53(60 \%) \quad$ Internet: $26(29 \%) \quad$ Television: $6(7 \%)$

Radio: 1 (1\%)

Newspaper: $1(1 \%) \quad$ Family/Friend: $3(3 \%)$

If you became ill after finding a tick, how likely would you be to seek medical help?
Very: $80(90 \%)$
Somewhat: $16(18 \%)$
A little: 11 (12\%)
Not at all: $6(7 \%)$ 
Appendix C

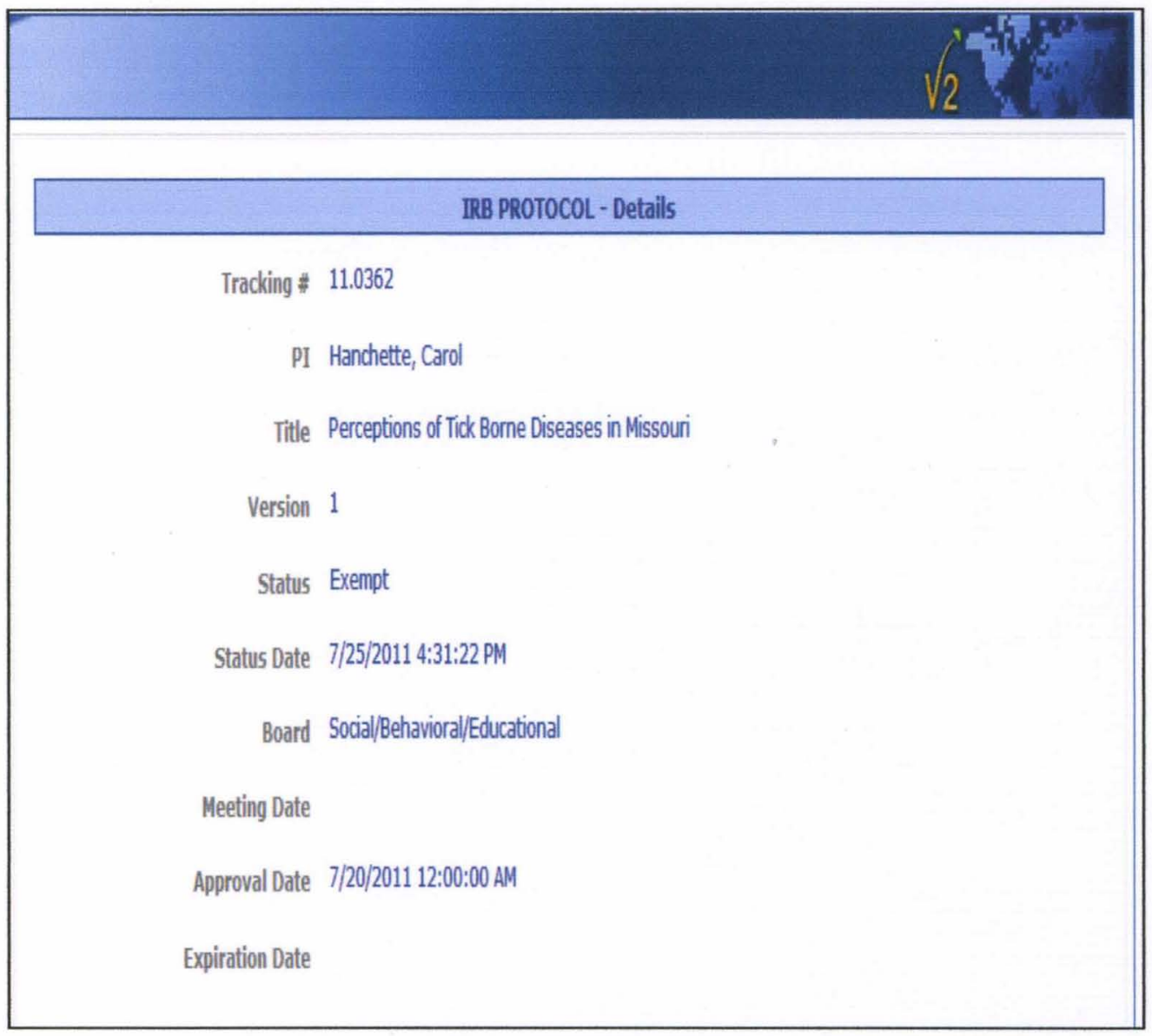




\section{CURRICULUM VITAE}

NAME: $\quad$ James Edward Nunn III

ADDRESS: $\quad 7403$ Beechview Way \#7

Louisville, KY 40219

DOB:

Memphis, Tennessee - October 21, 1985

EDUCATION\&

TRAINING:

B.S., Biology

University of Louisville, Kentucky

2004-2009

M.S., Applied Geography

University of Louisville, Kentucky

2010-2012

PROFESSIONAL

SOCIETIES: $\quad$ Member of Graduate Student Union 